\title{
STAT3 but not STAT5 contributes to the protective effect of electro-acupuncture against myocardial ischemia/reperfusion injury
}

Hui-Hui Guo ${ }^{1 \#}$, Xin-Yue Jing ${ }^{1 \#}$, Hui Chen ${ }^{2}$, Hou-Xi Xu ${ }^{1}$, Bing-Mei Zhu ${ }^{3 *}$

1 Key Laboratory of Acupuncture and Medicine Research of Ministry of Education,

Nanjing University of Chinese Medicine, Nanjing, 210023, Jiangsu, China;

2 Rehabilitation Medicine Department, YEDA Hospital of Yantai, Yantai, 264000,

Shandong, China;

3 Regenerative Medicine Research Center, West China Hospital, Sichuan University, Chengdu, 610041, Sichuan, China.

\# These authors have equal contribution

*Corresponding author

Prof. Bing-Mei Zhu

Present address: Regenerative Medicine Research Center, West China Hospital,

Sichuan University, Keyuan Road 4, Gaopeng Street, Chengdu, Sichuan,

P.R.China. 610041

Tel: +86-28-85164069(O)

Fax:+86-28-85164037

e-mail: zhubm64@hotmail.com

\section{Keywords}

Myocardial ischemia reperfusion (I/R) / STAT5/ STAT3/ Electro-acupuncture/

Cardioprotection

The total number of words : 9802 


\section{Abstract}

Late remote ischemia preconditioning (RIPC) and electro-acupuncture (EA) have both been suggested to reduce injury caused by myocardial ischemia/reperfusion (I/R). Our previous study has found that cardioprotection in RIPC is STAT5-dependent. Here, we aim to observe the effects of electro-acupuncture pretreatment (EAP) on I/R in the presence or absence of STAT5 in mice and investigate whether the protection of EAP is in a STAT5-dependent manner. In this study, EAP decreased myocardial infarction size (IS) /total area (TA) and rate of cardiomyocyte apoptosis. STAT5 was activated by EAP in the Stat $5^{f l f l}$ mice but not in the Stat 5 -cKO mice, whereas, STAT3 was activated by EAP only in the Stat $5-c K O$ but not in the Stat $5^{f l f l}$ mice. Differentially expressed genes (DEGs) regulated by EAP in the Stat $f^{f l f l}$ and the Stat5-cKO mice were quite distinct, indicating that EAP may activate IL-6/STAT3 signal in the absence of Stat5, and that EAP-induced cardioprotection against myocardial I/R injury was correlated with the activation of anti-apoptotic signaling and cardiomyocyte-survival signaling. Our results, for the first time, demonstrated that the protective effect of EAP was attributed to, but not dependent on, STAT5.

\section{Introduction}

It is known that myocardial ischemia/reperfusion (I/R) injury is a pathological phenomenon that can cause further cardiomyocyte death following blood restoration (Li et al, 2019; Chen et al, 2019). Remote ischemic preconditioning (RIPC) has been demonstrated as an intervention to attenuate ischemic-reperfusion (I/R) injury and protect myocardium for many years (Davidson et al, 2019; Ekeloef et al, 2019; Cho \& Kim , 2019; Heusch, 2015). Our recent study has shown that signal transducer and activator of transcription 5 (STAT5) plays a critical role in RIPC, and RIPC mediates cardioprotection by activating anti-apoptotic and cardiomyocyte-survival signaling in a STAT5-dependent manner (Chen et al, 2018). Electro-acupuncture (EA), as one of the Traditional Chinese Medicine (TCM) approaches, has been applied to treat many diseases clinically around the world (Painovich \& Longhurst, 2015). Increasing experimental and clinical evidences have confirmed EA's effectiveness on cardiovascular diseases ( Zhang et al, 2020; Ji et al, 2018; Huang et al, 2014; Fu et al, 2014; Zeng et al, 2018; Lu et al, 2016). A very recent article (Zhao et al, 2019) collected a total of 1651 patients with chronic stable angina and performed a clinical trial with acupuncture treatment. This study has shown that acupuncture as an auxiliary treatment method can alleviate clinical pain in patients with chronic stable 
angina, reduce the patient's anxiety and depression, and eventually improve the quality of life for these patients. Its underlying mechanisms have been known, include anti-apoptosis and anti-oxidative stress, as well as reducing inflammatory damage, calcium overload, and endoplasmic reticulum stress (Chen et al, 2019; Tang et al, 2019).

Studies, including our previous work, have shown that using electro-acupuncture before the event of ischemia-reperfusion, which is also called electro-acupuncture pretreatment (EAP), could protect cardiomyocytes by reducing the myocardial infarct size and regulating some molecular signaling, such as apoptosis and survival signaling (Huang et al, 2014; Lu et al, 2016). Given that the main molecule involved in RIPC in human patients is STAT5 (Cheung et al, 2006; Chen et al, 2018), we question whether EAP can also protect myocardium against ischemia-reperfusion through STAT5 signaling pathway. Therefore, we have employed the cardiomyocyte-specific Stat5 knockout (Stat5-cKO) mice and generated myocardial I/R model. EA is applied to the mice seven days before the I/R surgery. This study will determine whether EAP shares the same mechanism with RIPC and plays a preconditioning-like role as RIPC does on I/R injury. We have also carried on a genome-wide gene profiling to further find more candidate genes involved in the cardioprotection that results from EAP.

\section{Results}

\section{EAP reduced myocardial infarct size and attenuated cardiomyocytic apoptosis} to the same extent in both the Stat ${ }^{\text {flfl }}$ mice and the Stat5-cKO mice

We did not observe any difference in the daily behavior and cardiac performance between the $S t a t 5^{f l f l}$ mice and the Stat5-cKO mice, same as seen in our previous study (Chen et al, 2018). EA pretreatment was applied on PC6 acupoints in both Stat $5^{\text {flffl }}$ mice and Stat5-cKO mice for seven days before they received myocardial I/R surgery. We did not see any difference before or after EAP in their daily behavior and cardiac performance between these two genotypes. We then harvested the heart tissues after $\mathrm{I} / \mathrm{R}$ and measured myocardial infarct areas by TTC staining (Fig 1) and found that EAP significantly reduced infarct size in the $\operatorname{Stat} 5^{f l f l}$ mice $(44.6 \pm 1.3 \%$ without EAP vs. $31.2 \pm 5.1 \%$ with EAP, $P<0.05)$ and the Stat 5 - $c K O$ mice $(41.9 \pm 4.1 \%$ without EAP vs. $31.3 \pm 4.5 \%$ with EAP, $P<0.05$ ). There was no significant difference between the $S t a t 5^{f l f l}+\mathrm{EA}+\mathrm{I} / \mathrm{R}$ and the Stat5-cKO+EA+I/R mice.

TUNEL staining was performed to detect apoptosis in the myocardial cells. As 
shown in Fig 2, the Stat $5^{f l f l}+\mathrm{EA}+\mathrm{I} / \mathrm{R}$ group had fewer TUNEL positive cells compared to the Stat $^{f l / f l}+\mathrm{I} / \mathrm{R}$ group $(P<0.01)$. Likewise, the apoptotic myocardial cells were also significantly reduced in the Stat5-cKO+EA+I/R group compared to the Stat5-cKO+I/R group $(P<0.01)$.

Figure 1.

Figure 1. Acupuncture reduced myocardial infarct size.

A TTC staining was used to measure ischemic infarct area.

B The ratio of infarct size/ total area was calculated and presented as percentage.

Data information: In $\mathrm{B}$, data are presented as mean \pm SEM, data were analyzed by one-way ANOVA with Tukey's post hoc correction. Normal tissues are red, and ischemic infarct areas are pale white. ${ }^{*} P<0.05$, compared with Stat $^{f l / f l}+\mathrm{I} / \mathrm{R}$ group, $\# P<0.05$, compared with Stat5-cKO+I/R group.

Source data are available online for this figure.

Figure 2.

Figure 2. Effects of EAP on apoptosis of myocardial tissues in the Stat $5^{f l f l}$ and the Stat5-cKO mice.

A,B The apoptosis index was measured by TUNEL staining.

Data information: Values are mean \pm SEM, $\mathrm{n}=5$. $* * P<0.01$, compared with the Stat $5^{f l f l}+\mathrm{I} / \mathrm{R}$ group, \#\# $P<0.01$, in comparison with the Stat5-cKO+I/R group.

\section{EAP activated STAT5 in the $S t a t 5^{f l f l}$ mice but not in the Stat5-cKO mice under myocardial I/R condition}

To further explore whether the myocardial protection of EAP against I/R injury is STAT5 dependent, we examined protein levels of p-STAT5 in the heart tissues by western blotting. While EAP markedly increased p-STAT5/GAPDH in the Stat5 $5^{\text {flfl }}$ mice compared with the Stat $5^{f l f l}$ mice subjected to I/R, EA had no effect on STAT5 activation in the hearts of the Stat5-cKO mice (Fig 3A and B). This suggests that STAT5 may participate in the process of EAP protection against myocardial I/R injury.

\section{Figure 3.}

Figure 3. EAP activated STAT5 protein in the heart tissues of the Stat $5^{\text {fllfl }}$ but not the Stat5-cKO mice.

A The images of representative western blotting.

B Quantitative analysis of p-STAT5 protein in each group. 
Data information: In $\mathrm{B}$, data are presented as mean \pm SEM, data were analyzed by two-way ANOVA, Bonferroni's multiple comparison test, $\mathrm{n}=8$. ** $P<0.01$, compared with the Stat5 $5^{f l f l}+\mathrm{I} / \mathrm{R}$ group, \# $P<0.05$, in comparison with the Stat5-cKO+I/R group.

\section{IL-6/gp130/STAT3 signaling was activated by EAP in the absence of Stat5}

As described in our previous study (Chen et al, 2018) and shown in our current observation, STAT5 is a very important molecule in myocardial protection through RIPC or EAP against I/R injury. However, EAP did also display a protective role against myocardial I/R injury when STAT5 was absent in the mouse heart, suggesting that the EAP-induced myocardial protection may be STAT5-independent and some other proteins may be in charge of this function when STAT5 is missing. Considering the possibility of compensation by STAT3, we then evaluated the expression levels of STAT3 protein and p-STAT3 protein in the heart tissues of both Stat $5^{\text {fl/fl }}$ mice and Stat5-cKO mice. We discovered that the expression of p-STAT3 was increased in the Stat5-cKO+EA+I/R mice compared to the Stat5-cKO+I/R group, whereas this was not observed in the Stat $f^{f l f l}$ mice (Fig 4A). To understand the mechanism by which STAT3 was activated in this process, we further detected the upstream molecules of STAT3 and found that the mRNA level of IL-6 and gp130 were upregulated in the Stat5-cKO+EA+I/R mice compared to those in the Stat5-cKO+I/R mice, suggesting that EAP activated the IL-6/gp130/STAT3 pathway in the absence of Stat5 gene when the heart was exposed to myocardial I/R damage, a process not seen in the presence of Stat5 (Fig 4B).

Figure 4.

Figure 4. The expression of IL-6/gp130/STAT3 axis related molecules.

A The expression of STAT3 and p-STAT3 proteins was detected by western blotting.

B The expression of IL- 6 and gp130 mRNAs was performed by RT-PCR.

Data information: $* * p<0.01$, compared with the Stat $5^{f l f l}+\mathrm{I} / \mathrm{R}$; \#\# $P<0.01$, compared with the Stat $^{\text {fl/fl }}+\mathrm{EA}+\mathrm{I} / \mathrm{R} ; \& \& P<0.01$, compared with the Stat5-cKO+I/R, $\mathrm{n}=4-6 . \quad \mathrm{B} * * P<0.01$, compared with the Stat $^{f l f f l}+\mathrm{I} / \mathrm{R}$ group, \# $P<0.05$ compared with the Stat $5^{f l / f l}+\mathrm{EA}+\mathrm{I} / \mathrm{R}$ group, $\$ P$ $<0.05$ compared with the Stat $5-c K O+\mathrm{I} / \mathrm{R}$ group, $\mathrm{n}=3-4$.

4. Genome-wide analysis revealed gene expression profiles in both $S t a t 5^{\text {flfl }}$ mice and Stat5-cKO mice with or without EAP followed by myocardial I/R injury

To find the candidate genes participating in the EAP-induced protection against myocardial I/R injury, RNAs were extracted from the heart tissues and RNA-seq was 
performed using next generation high-throughput sequencing. With the Cufflinks package, we filtered out the top 30 differentially expressed genes (DGEs) by fold changes through comparing the $S t a t 5^{f l f f l}+\mathrm{I} / \mathrm{R}$ group with the $S t a t 5^{f l / f l}+\mathrm{EA}+\mathrm{I} / \mathrm{R}$ group and the Stat5-cKO+I/R group with the Stat5-cKO+EA+I/R group (Table 1A and B). First, we compared DEGs between the $S t a t 5^{f l f l}+\mathrm{I} / \mathrm{R}$ group and the $S t a t 5^{f l f l}+\mathrm{EA}+\mathrm{I} / \mathrm{R}$ group and between the $S t a t 5-c K O+\mathrm{I} / \mathrm{R}$ group and the $\operatorname{Stat} 5-\mathrm{K} O+\mathrm{EA}+\mathrm{I} / \mathrm{R}$ group. Venn diagrams were drew based on the list of filtered DEGs among four groups (Fig 5). The results showed that, compared with the $S t a t 5^{f l f l}+\mathrm{I} / \mathrm{R}$ group, 1052 genes were differentially expressed in the $S t a t 5^{f l / f l}+\mathrm{EA}+\mathrm{I} / \mathrm{R}$ group, and 1039 DEGs were obtained by comparing the Stat5-cKO+I/R group and the Stat5-cKO+EA+I/R group, in which 133 genes were overlapped by these two clusters. Among these 4 groups, only two genes, Hspa1a and Pttg1 were found to belong to all four groups, suggesting that STAT5-dependent genes and EAP-regulated genes were located in different categories. We further analyzed these genes and further tried to understand mechanisms by which myocardial I/R pathology occurs in the presence or absence of Stat 5 and how EAP protects myocardial I/R injury through regulating gene expressions. We found that among the EAP up-regulated genes and down-regulated genes in the presence of STAT5 $\left(\right.$ Stat $^{f l / f l}+\mathrm{I} / \mathrm{R}$ vs Stat $\left.5^{f l / f l}+\mathrm{EA}+\mathrm{I} / \mathrm{R}\right)$, lots of genes (such as Fosb, Fos, Cxcl5, Cxcl, Egr1, Egr2, Nr4a3, Socs3, Ccn5, Myl4, Zhx2, Dkk3, and Dynll1 ) have been reported to participate in the protection against the myocardium ischemia, I/R, cardiac hypertrophy or hypoxia in the literatures (Wu et al, 2017; Kubota et al, 2019; Wang et al, 2018; Sun et al, 2019; Ma et al, 2020; Oba et al, 2012; Tian et al, 2020; Stobdan et al, 2015; Bos et al, 2012; Zhai et al, 2018; El-Magd et al, 2017). These DEGs belong to many functional pathways, such as the JAK/STAT signaling pathway, the TNF signaling pathway, apoptosis, or the NF-kappa B signaling pathway. In the other hand, when STAT5 is absent, we found that among the top 30 DEGs generated by comparing the Stat5-cKO+EA+I/R group with the Stat5-cKO+I/R group (Table 1B), Rps6, Mmp3, pttg1, Rac2 had a strong relationship with the IL-6/STAT3 signaling pathway, as reported previously in the literatures (Dern et al, 2019; Wu et al, 2020; Calamaras et al, 2015; Sharma et al, 2019; Abilleira et al, 2006; Zhu \& Sun et al, 2017; Huang et al, 2018; Lai et al, 2017; Shirakawa et al, 2018; Wen et al, 2015).

Figure 5.

Figure 5. Venn diagrams and clustering analysis of RNA-seq results. 
Data information: Venn diagrams were drawn based on our RNA-seq data sets. Blue circle indicates the numbers of genes up- and down-regulated in the $S t a t 5^{f l / f l}+\mathrm{EA}+\mathrm{I} / \mathrm{R}$ group (vs. the Stat $5^{f l f f l}+\mathrm{I} / \mathrm{R}$ group); pink circle represents the numbers of up- or down-regulated genes in the Stat5-cKO+EA+I/R group (vs. Stat5-cKO+I/R group). 133 genes were overlapped by these two clusters.

To further understand the potential pathways involved in the STAT5-related DEGs and the EAP-modified DEGs under I/R, we then carried out pathway analyses for these DEGs. Encyclopedia of Genes and Genomes (KEGG) pathway analyses were performed using DAVID Bioinformatics Resources, and the top 20 pathways were outlined in Fig 6.

Figure 6.

Figure 6. KEGG pathway analysis of up- and down-regulated genes in the heart tissues in the presence or absence of $\operatorname{Stat} 5(\mathrm{~A}-\mathrm{C})$.

A The top 20 KEGG pathways were drawn from the 919 DEGs genes by comparing the Stat $5^{f l / f l}+\mathrm{I} / \mathrm{R}$ group and the $S t a t 5^{f l / f l}+\mathrm{EA}+\mathrm{I} / \mathrm{R}$ group shown in Figure 5 .

B The top 20 KEGG pathways were drawn from the 906 DEGs genes by comparing Stat5-cKO+I/R group and Stat5-cKO+EA+I/R group shown in Figure 5 .

$\mathrm{C}$ The top 20 KEGG pathways were drawn from the 133 co-regulated genes shown in Figure 5.

KEGG pathway analyses suggested that, in the presence of Stat5, EAP-activated genes were mainly enriched in the JAK-STAT signaling pathway, the TNF signaling pathway, cytokine-cytokine receptor interaction, the IL-17 signaling pathway, the NF-kappa B signaling pathway, and the MAPK signaling pathway (Fig 6A). They may work together to protect the myocardium from I/R injury (Castejon et al, 2019; Yuan et al, 2019; Świerkot et al, 2015). In contrast, in the Stat5-cKO mice, the myocardial protection of EAP mainly concentrated in Ribosome pathways, thermogenesis, and the oxidative phosphorylation pathway (Fig 6B). Moreover, we also analyzed the top 20 KEGG pathways of the 133 overlapped genes (Fig 6C), showing that the EAP-regulated part of the STAT5-independent genes were mainly located in inflammation related pathways (such as the IL-7 signaling pathway, human T-cell leukemia virus 1 infection, antigen processing and presentation, and the TNF signaling pathway).

Table 1.

\section{Apoptotic and survival signaling were regulated by EAP only in the presence of STAT5.}


Based on the above genome-wide profiling data, we detected that EAP could activate apoptotic and survival signaling in mice with I/R injury. To further validate these findings, we studied apoptotic and survival related protein expression in myocardial tissues of the Stat5 $5^{f l f l}$ and the Stat5-cKO mice with EAP. The results showed that the expression of Bcl-2 and Bcl-xL were significantly increased in the Stat $5^{f l / f l}+\mathrm{EA}+\mathrm{I} / \mathrm{R}$ group compared with the $\operatorname{Stat} 5^{f l / f l}+\mathrm{I} / \mathrm{R}$ group $(P<0.05)$, whereas the expression of Cyt $\mathrm{C}$ did not change between these two groups (Fig 7). In contrast, we did not detect significant differences in these protein expressions in the hearts of Stat5-cKO mice, with or without EAP, suggesting that STAT5 is required for regulating anti-apoptotic signaling induced by the EAP stimulus. We then detected the level of IL-10, an important cytokine in cardio-protection, and its related proteins, PI3K, AKT, and p-AKT (Fig 8). The results showed that IL-10 and p-AKT were elevated by EAP in the presence but not absence of STAT5, however IL-10 was up-regulated in the hearts of both $S t a t 5^{f l f l}$ mice and Stat5-cKO mice with EAP. These results indicate that the protective effect of EAP against myocardial I/R injury in survival signaling is partially STAT5-dependent.

Figure 7.

Figure 7. The expression of apoptosis-related proteins.

A,B Western blotting was used to detect the level of Bcl-2, Bcl-XL and Cyt $\mathrm{C}$ in each group. Data information: ** $P<0.01$, compared with Stat $^{f l l f l}+\mathrm{I} / \mathrm{R}$ group, $\mathrm{n}=6$.

Figure 8.

Figure 8. The expression of survival signaling-related proteins.

A,B Western blotting was used to detect the level of IL-10, p-AKT, and AKT in each group. Data information: $* P<0.05$, compared with Stat $^{f l / f l}+\mathrm{I} / \mathrm{R}$ group, $\# P<0.05$, in comparison with Stat $5-c K O+\mathrm{I} / \mathrm{R}$ group, $\mathrm{n}=6$.

\section{Discussion}

Ischemic heart disease is still the major cause of premature mortality and disability worldwide (Gupta \& Wood, 2015). As a clinically effective method against myocardial I/R injury, early coronary reperfusion reduces the infarct size, but reperfusion by revascularization initiates a cascade of events that can accelerate and 
extend post-ischemic injury (Binder et al, 2015; Yellon \& Hausenloy, 2017). Remote ischemia preconditioning (RIPC) has been confirmed to be an effective and clinically applicable perioperative method to reduce the risk of myocardial injury (Hausenloy et al, 2019; Ekeloef et al, 2019). In our previous study, we have found that STAT5 plays a key role in the RIPC-mediated late cardio-protection through anti-apoptotic signaling and the PI3K/AKT survival pathway (Chen et al, 2018). Similar to RIPC, EA pretreatment at acupoint PC6 like a late stimulating can also protect myocardium under certain disease conditions by stimulating multiple functional pathways.

In the present study, we explored the role of STAT5 in EAP-induced myocardial protection against ischemia-reperfusion by employing cardiomyocyte-specific Stat5-cKO mice. We observed that EAP could reduce the infarct size and myocardial cell apoptosis in both Stat $^{\text {fllfl }}$ and Stat5-cKO mice (Fig 1 and Fig 2), suggesting that STAT5 is not required in the cardioprotection of EAP against myocardial I/R injury. To understand how EAP played a protective role in the loss of Stat5, we performed RNA sequencing with the I/R injured heart tissue. We found that EAP can increase the mRNA expressions of Fosb, Fos, Cxc15, Cxcl1, Egr1, Egr2, Nr4a3, and Socs3, which were reported to be involved in anti-apoptosis, anti-inflammation, antioxidation, and STAT3/5 signaling when STAT5 is intact. Fosb and Fos, as two components of AP-1, can protect against myocardial I/R injury via anti-apoptosis, anti-oxidative stress, and anti-inflammatory activation (Wingelhofer et al, 2018; Walker et al, 2014; Walker et $a l, 2013)$. Cxcl5 and Cxcl1 are two members in the CXC family of chemokines and have been shown to improve cell survival after myocardial injury through the promotion of wound healing by changing neutrophil infiltration and activating the phosphatidylinositol 3-kinase pathway (Cai et al, 2020; Zhou et al, 2020). Egr1 and Egr2 belong to early growth response protein $1 / 2$. They can induce myocardial injury by regulating myocardial autophagy, cell death, and the progression of myocardial fibrosis (Wang et al, 2018; Cao et al, 2010). Nr4a3, a member of the NR4A orphan nuclear receptor, plays a protective role during acute myocardial infarction by suppressing inflammatory responses via the JAK2-STAT3/NF-kB pathway (Obana et al, 2010; Walker et al, 2014). Socs3, a negative effector of STAT3 signaling, is an NF-kappaB/IKK-induced gene. IKK-mediated NF-kappaB activation can coordinately illicit negative effects on STAT signaling (Gopinath, 2017). Aside from the above up-regulated genes, Hspala and Hspa1b are also important factors during the restoration of myocardial I/R injury (Jiang et al, 2014; Wilhide et al, 2011) and 
appear to be up-regulated by EAP. In addition, among the down-regulated DEGs, Ccn5 is an anti-hypertrophic and anti-fibrotic factor during adverse cardiac remodeling. It can be regulated by activating JAK/AKT/STAT3-signaling in luminal-type (ER-positive) breast cancer (BC) cells (Haque et al, 2018). Myl4 (myosin light polypeptide 4) is a key gene for atrial contractile, electrical, and structural integrity (Udoko et al, 2016). Zhx2, as one of the transcription factors, can improve macrophage survival and pro-inflammatory functions in atherosclerotic lesions (Tian et al, 2020; Alfonso-Jaume et al, 2006). Hic1, a transcriptional repressor that modulates the expression of cell-cycle genes, can affect heart function and be regulated by the IL-6/STAT3 pathway (Wen et al, 2019; Sulston et al, 2017). Gas1, pttg1, Nrtn, and Tnfrsf25 have also been identified as key molecules in the heart tissue by regulating tissue formation, metabolism, apoptosis of cardiomyocytes, and the interaction of cytokine-cytokine receptor in the JAK/STAT pathway (Tang et al, 2019; Jiang et al, 2019; Saddic et al, 2018).

In short, many of the genes and pathways found in our RNA-seq have been attributed to MI or I/R injury and are regulated by EAP in the Stat $5^{\text {fl/fl }}$ mice. This indicates that EAP can mimic RIPC and play a protective role against I/R injury by altering functional gene expression in the presence of STAT5.

Intriguingly, in the Stat5-cKO mice, EAP regulated different DEGs, of which Rps6, Mmp3, Pttg1, and Rac2 are involved in the IL-6/STAT3 signaling pathway. In addition, ribosomal, thermogenesis, and oxidative phosphorylation pathways are activated by EAP in the absence of STAT5. Among these DGEs, Mmp3, known as matrix metallopeptidase 3 , encodes a member of the matrix metalloproteinase family of the extracellular matrix-degrading enzymes that are involved in tissue remodeling, wound repair, progression of atherosclerosis, and tumor invasion (Abilleira et al, 2006). Recent findings indicate that the binding of STAT3 to the MMP promoter promotes the transcription of Mmp3 gene, which accounts for IL-6-induced MMP gene activation (Zhu \& Sun, 2017). Pituitary tumor transforming 1 (pttg1) has been reported as an oncogene that is originally cloned from rat pituitary tumor cells. Huang et al. have demonstrated that pttg1 expression is regulated by IL-6 via the direct binding of activated STAT3 to the pttg1 promoter in LNCa P cells. Rac2, one of the Rac family members, is expressed mainly in the hematopoietic cells (Huang et al, 2018). Rac protein can promote glioblastoma tumor sphere-induced angiogenesis in the zebrafish exnotransplantation model. Knockdown of Rac protein reduces the 
tumorigenesis in the mouse model in vivo (Lai et al, 2017). Lai et al. have detected reduced STAT3 activation in the Rac down-regulated glioblastoma cells without affecting STAT5 activation. Osteopontin (OPN) is also known as secreted phosphoprotein 1 (Spp1). High levels of intracellular galectin-3 expression are essential for transcriptional activation of Spp1 in STAT3-mediated polarization toward M2 macrophages after MI (Shirakawa et al, 2018; Wen et al, 2015). The phosphorylation sites of ribosomal protein S6 (Rps6) have been mapped to five clustered residues, which play an important role in protein synthesis in cardiac myocytes and cardiac function (Dern et al, 2019; Wu et al, 2020; Calamaras et al, 2015; Sharma et al, 2019).

Through RNA-seq profiling, we expect different mechanisms were involved in EAP protection against myocardial I/R injury between Stat5 $5^{\text {flfl } l}$ and Stat5-cKO mice. Combined with the molecular biological data in this study, these results support our hypotheses that EAP may activate STAT3 in the absence of STAT5 and function as a protective approach for I/R.

In fact, multiple studies have demonstrated that in the absence of a given STAT member, receptors will recruit other STAT members instead (Hennighausen et al, 2018; Yu et al, 2010; Valle \& Soto et al, 2020; Hosui et al, 2009; Hin et al, 2020; Friedbichler et al, 2012). STAT5 and STAT3 are two proteins of STAT family that show high homology in their functional domains, can be activated by different mechanisms, and bind to distinct loci to regulate specific target gene expression (Wingelhofer et al, 2018). STAT3 and STAT5 proteins can also bind to the same regulatory oncogenic loci, resulting in compensatory or antagonistic signaling (Walker \& Xiang, 2014; Walker et al, 2013). Nevertheless, the role of STAT5 and STAT3 in myocardial I/R injury by EAP have not been studied yet. Interestingly in our study, p-STAT3 protein has significantly increased in the Stat5-cKO+EA+I/R group compared to the $S t a t 5^{f l f l}+\mathrm{EA}+\mathrm{I} / \mathrm{R}$ group (Fig 4), suggesting that EAP activates STAT3, which then contributes to protecting the myocardium against I/R injury in the Stat5-cKO mice. Furthermore, RNA-seq data suggest that the ribosome pathway is significantly activated by EAP. It may also link to the cardioprotection in the absence of Stat5. In this pathway, we found that Rps6 and Rpl3-ps1 are upregulated by EAP in the Stat5-cKO mice. They were reported before to be regulated by the IL-6/STAT3 signaling (Dern et al, 2020; Meyuhas et al, 2015). To confirm this, we determined the mRNA expression in the IL-6/gp130 receptor system, which is an important activator 
of STAT3, and have found that the mRNA expressions of gp130 and IL-6 are increased by EAP only in the Stat5-cKO mice (Fig 4B), suggesting that when STAT5 is deleted, IL-6/gp130/STAT3 signaling gets activated to play role in the protection against myocardial I/R.

Growing evidence has demonstrated the favorable and protective role of STAT3 in the heart (Harhous et al, 2019; Nakao et al, 2020). To understand the mechnisms by which STAT3 contributes to protection of EAP against I/R imjury, we determined the apoptotic and survival signaling in the heart tissue of the mice. STAT3 is involved in decreasing cardiac I/R injury by reducing apoptosis or increasing anti-apoptotic signaling, increasing expression of cardioprotective proteins, decreasing ROS generation, and inhibiting autophagy (Harhous et al, 2019). We found that EAP promoted the expression of anti-apoptotic proteins Bcl-2 and Bcl-xl and p-AKT in the Stat $5^{f l f l}+\mathrm{I} / \mathrm{R}$ mice, but not in the Stat5-cKO+I/R mice. However, the expression of IL-10 protein was increased in both the Stat $5^{f l f l}$ and the Stat5-cKO mice when EAP was applied followed by I/R injury. IL-10 is one of the important anti-inflammatory cytokines which can be produced by most cells and affect the growth and differentiation of various hematopoietic cells and increase cell proliferation, angiogenesis, and immune evasion (Zhen et al, 2018; Hodge et al, 2005). Our previous study has shown that IL-10 RIPC can activate the expression of IL-10, p-AKT, Bcl-2, and Bcl-xl to protect the myocardium (Chen et al, 2018). Recently, Takahashi $\mathrm{J}$ et al. has shown that interleukin-22, one member of the IL-10 cytokine family, activates myocardial STAT3 signaling pathway and prevents myocardial I/R injury in the mouse model of ischemia reperfusion injury (Takahashi et al, 2020). Other studies have also shown that the IL-6 and IL-10 family of cytokines are the main mediators that activate intrinsic JAK/STAT3 signaling to induce the transcription of genes enabling survival and proliferation of cells (Harhous et al, 2019; Huynh et al, 2017). Activated STAT3 can regulate the expression of genes (such as MMP2, MMP9, and Ubc13) and therefore underpin the molecular cross-talk between these genes (Pipicz et al, 2018). When the Stat5-cKO mice were given a stress of myocardial I/R injury in this study, Mmp3, Ubb, and Myh7 genes that are closely correlated with STAT3 pathway were altered by EAP (Table 1b), therefore STAT3 might have played a vital role in cardio-protection by controlling these gene's expression. In addition, some studies have identified that activation of STAT3 can improve the expression VEGF (Huynh et al, 2019; Johnson et al, 2018). We have 
detected the expression of VEGF-A, but there is no difference among our four groups (Appendix Fig 9). To a certain extent, these results show that the activation of STAT3 by EAP may be not enough for elevating angiogenesis in the Stat5-cKO mice.

In summary, the present study demonstrates that EAP approach to protecting against myocardial I/R injury by reducing the myocardial infarct area and activating anti-apoptotic and survival signaling. STAT5 is involved in this process but the protection is not STAT5 dependent. STAT3 may compensate the function of STAT5 by activating the IL-6/gp130/STAT3 signaling pathway in the absence of STAT5. This study suggests, for the first time, that EAP can mimic RIPC but function more effectively in cardio-protection against I/R injury through multiple pathways.

\section{Materials and Methods}

\section{Antibodies and reagents}

Antibodies for p-STAT5 (Try694), p-STAT3 (Try705), STAT3, p-AKT (Ser473), AKT, Cytochrome c (Cyt c), Bcl-xL, Bcl-2, and GAPDH were purchased from Cell Signaling Technology. Antibodies for IL-10, and $\beta$-actin were purchased from Abcam (Cambridge, UK). The in-situ cell-death detection kit to assess apoptosis, POD (TUNEL), was purchased from Roche (Lewes, UK). The triphenyltetrazolium chloride (TTC) was purchased from Sigma-Aldrich (St. Louis, MO, USA).

\section{Conditional and inducible cardiomyocyte-specific Stat5-cKO mice}

As previously described, the Stat 5 mice $\left(\right.$ Stat $\left.5^{f l / f l}\right)$ were kindly provided by Dr. Hennighausen (NIDDK, NIH), and Tnnt2-Cre male mice (Tnnt2 ${ }^{\text {Cre }}$ ) were obtained from Bin Zhou (Shanghai Institutes for Biological Sciences of the Chinese Academy of Sciences) as gifts (Chen et al, 2018). The Stat5 knockout mice (Stat5-cKO) were generated by mating these two genotypes. Doxycycline hyclate (Sigma-Aldrich, St. Louis, MO, USA) was administrated through adding into the drinking water of mice at a concentration of $2 \mathrm{mg} / \mathrm{ml}$ for 7 days. The method used for genotyping has been described in our previous article (Chen et al, 2018).

\section{Study groups}

The mice were divided into four groups: Stat $5^{f l / f l}+\mathrm{I} / \mathrm{R}$, Stat $5^{f l f l}+\mathrm{EA}+\mathrm{I} / \mathrm{R}$, Stat $5-c K O+\mathrm{I} / \mathrm{R}$, and Stat $5-c K O+\mathrm{EA}+\mathrm{I} / \mathrm{R}$. Stat $5^{f l f l}+\mathrm{I} / \mathrm{R}$ and $S t a t 5-c K O+\mathrm{I} / \mathrm{R}$ groups were subjected to left anterior descending (LAD) coronary artery occlusion for 30min, and then reperfused for $180 \mathrm{~min}$. Stat $5^{f l / f l}+\mathrm{EA}+\mathrm{I} / \mathrm{R}$ and $S t a t 5-c K O+\mathrm{EA}+\mathrm{I} / \mathrm{R}$ groups were subjected to EAP 7 days before the LAD ligation. All murine studies were carried out in accordance with the EU Directive 2010/63/EU for the protection of 
animals used for experimental purpose. All experiments were approved by the Institute for Animal Care and Use Committee at Nanjing University of Chinese Medicine.

\section{In vivo experiments}

Prior to the myocardial $\mathrm{I} / \mathrm{R}$ injury experiment, Stat $5^{f l f l}+\mathrm{EA}+\mathrm{I} / \mathrm{R}$ and Stat5-cKO+EA+I/R mice were pretreated with EA for a total of 7 days. EA was performed at billateral PC6 (also called Neiguan) acupoints based on the previous study (Huang et al, 2014). The PC6 acupoint is located in the interosseal muscles between the radius and ulna of the forelimb, $3 \mathrm{~mm}$ proximal to the wrist crease, according to the textbook of experimental acupuncture in animals (Huang et al, 2014). Mice were anaesthetized with isoflurane (5\%) and maintained with 1-2\% isoflurane in pure oxygen. The sterilized disposable stainlesssteel acupuncture needles $(0.18 \mathrm{~mm} \times 13 \mathrm{~mm}$, Beijing Zhongyan Taihe Medical Instruments Factory, Beijing, China) were inserted a depth of $1-2 \mathrm{~mm}$ into the muscle layer at bilateral PC6 simultaneously using Han's EA instrument (Han Acuten, WQ1002F, Beijing, China) and alternating dense and disperse mode, with a frequency of $2 / 15 \mathrm{~Hz}$ at an intensity level of $0.5-1 \mathrm{~mA}$, at a stimulation period of 20 minutes, once a day, for a total 7 days. The mice in the $S t a t 5^{f l f l}+\mathrm{I} / \mathrm{R}$ group and the $\operatorname{Stat} 5-c K O+\mathrm{I} / \mathrm{R}$ group were restrained for 20 minutes without EA stimulation.

The I/R operation was performed as described in the previous studies (Chen et al, 2018; Huang et al, 2014). Briefly, all the mice were given 5\% isoflurane and then maintained with $2 \%$ isoflurane in a mixture of $70 \% \mathrm{~N}_{2} \mathrm{O}$ and $30 \% \mathrm{O}_{2}$ for anesthesia. Under the anesthetized state, the mice were subjected to a left thoracotomy and LAD ligation with a slipknot using 6-0 silk sutures transiently at 2 to $3 \mathrm{~mm}$ below the left auricle, resulting in arterial occlusion, as evidenced by myocardial blanching and electrocardiographic abnormalities (ST-segment elevation and QRS complex widening) (Chen et al, 2018). After $30 \mathrm{~min}$, reperfusion was performed by quickly releasing and removing the suture and continued for $3 \mathrm{~h}$. In the sham-operation group, the same procedure was performed except for the LAD ligation. Mice were sacrificed after surgery and the heart specimens were harvested.

\section{Determination of infarct size}

At the end of the protocol, sections of mouse heart were perfused for 1-2 min with $2 \mathrm{ml}$ of $2 \%$ TTC (Sigma-Aldrich Co., St. Louis, MO, USA) in phosphate-buffered saline (PBS) and then incubated in an identical solution at $37^{\circ} \mathrm{C}$ 
for $15 \mathrm{~min}$. After incubating, slices were placed in $4 \%(\mathrm{v} / \mathrm{v})$ paraformaldehyde at $4{ }^{\circ} \mathrm{C}$ for $12 \mathrm{~h}$. TTC stained area (red, normal area) and non-stained areas (white, infarct area) were photographed. The infarcted area was quantified using Image-Pro Plus 6.0 software (NIH, USA). All analyses of infarct size were performed by two investigators who were blinded with the information regarding group assignments.

\section{Apoptosis measurements}

TUNEL staining method was used to detect cell apoptosis of cardiac tissue in each group. All the protocols were the same as previously described (Chen et al, 2018). Heart tissues were harvested and embedded with OCT (Thermo Scientific ${ }^{\mathrm{TM}}$, USA). The $8 \mu \mathrm{m}$ thick tissues were subjected to TUNEL staining according to the manufacturer's instructions for an In-Situ Cell Death Detection Kit (Cat. 11684817910, Roche Diagnostics, Indianapolis, IN, USA). Sections were then visualized with a fluorescence microscope (Nikon, Japan) with parallel positive control (DNase-I) and negative control (label solution only).

\section{Western blotting}

Whole ventricle samples were lysed with RIPA buffer supplemented with a protease inhibitor cocktail and a phosphatase inhibitor cocktail (Chen et al, 2018). Homogenates were centrifuged at $14,000 \times \mathrm{g}$ for $10 \mathrm{~min}$ at $4{ }^{\circ} \mathrm{C}$, and supernatants were stored at $-80{ }^{\circ} \mathrm{C}$ until further uses. Protein concentrations were determined using a BCA protein assay (Pierce). Protein was mixed with $5 \times$ Laemmli loading buffer and heated at $95{ }^{\circ} \mathrm{C}$ for $10 \mathrm{~min}$. Equal amount of protein was subjected to SDS-PAGE and transferred to polyvinylidene fluoride (PVDF) membranes. Immunoblots were performed using appropriate primary antibodies against Bcl-xL (1:1000, Cell Signaling, \#2762), Bcl-2 (1:1000, Cell Signaling, \#3498), Cyt c (1:1000, Cell Signaling , \#6808), Phospho-STAT5 (1:1000, Cell Signaling , \#9662), STAT5(1:1000, Cell Signaling , \#3421), Phospho-STAT3 (1:1000, Cell Signaling , \#2775), STAT3 (1:1000, Cell Signaling, \#2612), Phospho-AKT (1:1000, Cell Signaling , \#9662), AKT (1:1000, Cell Signaling , \#9608), IL-10 (1:1000, Cell Signaling , \#4351), $\beta$-actin (1:1000, Cell Signaling, \#1721), or GAPDH (1:1000, Cell Signaling , \#1752) overnight at $4{ }^{\circ} \mathrm{C}$, then incubated with a secondary antibody for two hours at room temperature. Western blot band intensities were quantified using SuperSignal West Pico Chemiluminescent substrate (Pierce).

\section{q-PCR analysis}

Three micrograms of RNA were converted to cDNA using reverse transcriptase 
and random primers (11121ES60, Yeasen Biotech Co., Ltd., China). For PCR analysis, the samples were amplified in duplication using SYBR Green (Vazyme, Q431-02) with $200 \mathrm{nM}$ of gene-specific primers and run on the CFX amplifier (MX3000P, Stratagene, La Jolla, CA, USA) according to the manufacturer's protocol. Data were analyzed by the threshold cycle $(\mathrm{Ct})$ relative-quantification method. The primer sequences were as follow: interleukin-6 (IL-6, forward: GACTTCACAGAG GATACCACCC, reverse: GACTTCACAGAGGATACCACCC); gp130 (forward: GAGCTTCGAGCCATCCGGGC, reverse: AAGTTCGAGCCGCGCTGGAC); Actin (forward: reverse:

\section{TGCTGGAAGGTGGACAGTGA).}

\section{RNA-seq and computational analysis for RNA-seq data}

To further explore possible changes in transcriptome profile caused by EAP against myocardial I/R injury in the Stat5 knockout mice, RNA-seq for the mouse heart tissues were performed using next generation high throughput sequencing method (Illumina HiSeq 2000, Illumina). Total RNAs were isolated. The RNA-seq protocol was described in our previous study (Fu et al, 2017).

Data analysis was performed as previously described (Fu et al, 2017). Quality of raw sequencing data was assessed by FASTQ files. We used the Cufflinks program and the Cuffdiff program to assemble individual transcripts and differential transcript expression analysis. The pathways were analyzed using the DAVID Bioinformatics Resources. Genes with lower than 1.0 FPKM (average fragments perkilobase of transcript per million fragments mapped) filtered out. Up-regulated and down-regulated genes were defined as a relative transcription level of above Log2 fold change $(\mathrm{FC}) \geq| \pm 1|$ and $P$ value $<0.05$.

\section{The paper explained}

\section{Problem}

Our recent study has shown that signal transducer and activator of transcription 5 (STAT5) plays a critical role in RIPC, and RIPC mediates cardioprotection by activating anti-apoptotic and cardiomyocyte-survival signaling in a STAT5-dependent manner (Chen et al, 2018). Studies, including our previous work, have shown that using electro-acupuncture before the event of ischemia-reperfusion, which is also called electro-acupuncture pretreatment (EAP), could protect cardiomyocytes by reducing the myocardial infarct size and regulating some molecular signaling (Huang et al, 2014; Lu et al, 2016). Given that the main molecule involved in RIPC in human patients is STAT5 (Cheung et al, 2006; Chen et al, 2018), we question whether EAP shares the same mechanism with RIPC and plays a preconditioning-like role as RIPC does on I/R injury. 


\section{Result}

The present study demonstrates that EAP can protect against myocardial I/R injury by reducing the myocardial infarct area and activating anti-apoptotic and survival signaling. STAT5 is involved in this process but the protection is not STAT5 dependent. STAT3 may compensate the function of STAT5 by activating the IL-6/gp130/STAT3 signaling pathway in the absence of STAT5. We revealed, for the first time, that EAP can mimic RIPC but function more effectively in cardio-protection against $\mathrm{I} / \mathrm{R}$ injury through multiple pathways.

\section{Impact}

This study will provide new scientific experimental data for acupuncture protecting against I/R injury.

\section{Statistics}

SPSS18.0 statistical software was utilized for statistical analysis. All data were presented as the mean \pm standard error of mean (SEM). The significance of the differences was determined by Student's t-test or one-way analysis of variance (ANOVA) with the least significant difference post hoc test when equal variances were assumed or with Bonferroni test post hoc when equal variances were not assumed. $P<0.05$ was considered statistically significant.

\section{Data availability}

The data supporting this study is available from the corresponding author upon reasonable request. RNA-Seq raw data is avilable in the National Center for Biotechnology Information

(NCBI) Gene Expression Omnibus (GEO) with the accession number GSExxxxx (https: // www. ncbi. nlm.nih.gov/geo/query/acc.cgi?acc=GSExxxxx).

Expanded View for this article is available online

\section{Acknowledgements}

This research was supported by the National Key R\&D Program of China (No. 2019YFC1709003), the National Natural Science Foundation of China (Grant No. 81870224). We thank Dr. Wanxin Liu (Washington DC, USA) for language editing.

\section{Author contribution}

Bing-mei Zhu and Xin-yue Jing conceived and supervised experiments. Hui-hui Guo, Xin-yue Jing, Hui Chen and Bing-mei Zhu wrote and edited the manuscript. Hui Chen and Hui-hui Guo performed experiments and analyzed data. Hou-xi Xu carried out the bioinformatic analyses for RNA-seq.

\section{Conflict of interest}

The authors declare that they have no conflict of interest. 


\title{
supplementary material.
}

\author{
manuscriptID_Figure 9 .
}

\section{References}

Abilleira S, Bevan S, Markus HS (2006) The role of genetic variants of matrix metalloproteinases in coronary and carotid atherosclerosis. J Med Genet 43(12):897-901.

Alam MJ, Gupta R, Mahapatra NR, Goswami SK (2020) Catestatin reverses the hypertrophic effects of norepinephrine in $\mathrm{H} 9 \mathrm{c} 2$ cardiac myoblasts by modulating the adrenergic signaling. Mol Cell Biochem 464(1-2):205-219.

Alfonso-Jaume MA, Bergman MR, Mahimkar R, Cheng S, Jin ZQ, Karliner JS, Lovett DH (2006) Cardiac ischemia-reperfusion injury induces matrix metalloproteinase-2 expression through the AP-1 components FosB and JunB. Am J Physiol Heart Circ Physiol 291(4):H1838-46.

Abilleira S, Bevan S, Markus HS (2006) The role of genetic variants of matrix metalloproteinases in coronary and carotid atherosclerosis. J Med Genet 43(12):897-901.

Bos JM, Subramaniam M, Hawse JR, Christiaans I, Rajamannan NM, Maleszewski JJ, Edwards WD, Wilde AA, Spelsberg TC, Ackerman MJ (2012) TGF $\beta$-inducible early gene-1 (TIEG1) mutations in hypertrophic cardiomyopathy. J Cell Biochem 113(6):1896-903.

Binder A, Ali A, Chawla R, Aziz HA, Abbate A, Jovin IS (2015) Myocardial protection from ischemia-reperfusion injury post coronary revascularization. Expert Rev Cardiovasc Ther. 13(9):1045-57.

Chen J, Luo Y, Wang S, Zhu H, Li D (2019) Roles and mechanisms of SUMOylation on key proteins in myocardial ischemia/reperfusion injury. J Mol Cell Cardiol 134:154-164.

Cho YJ, Kim WH (2019) Perioperative Cardioprotection by Remote Ischemic Conditioning. Int J Mol Sci 20(19). pii: E4839.

Chen H, Jing XY, Shen YJ, Wang TL, Ou C, Lu SF, Cai Y, Li Q, Chen X, Ding YJ, Yu XC, Zhu BM (2018) Stat5-dependent Cardioprotection in Late Remote Ischemia Preconditioning. Cardiovasc Res 114(5):679-689.

Cheung MM, Kharbanda RK, Konstantinov IE, Shimizu M, Frndova H, Li J, Holtby HM, Cox PN, Smallhorn JF, Van Arsdell GS, Redington AN (2006) Randomized controlled trial of the effects of remote ischemic preconditioning on children undergoing cardiac surgery: first clinical application in humans. J Am Coll Cardiol 47(11):2277-82.

Castejon ML, Sánchez-Hidalgo M, Aparicio-Soto M, Montoya T, Martín-LaCave I, Fernández-Bolaños JG, Alarcón-de-la-Lastra C (2019) Dietary oleuropein and its new acyl-derivate attenuate murine lupus nephritis through HO-1/Nrf2 activation and suppressing JAK/STAT, NF-kB, MAPK and NLRP3 inflammasome signaling pathways. J Nutr Biochem 
74:108229.

Calamaras TD, Lee C, Lan F, Ido Y, Siwik DA, Colucci WS (2015) The lipid peroxidation product 4-hydroxy-trans-2-nonenal causes protein synthesis in cardiac myocytes via activated mTORC1-p70S6K-RPS6 signaling. Free Radic Biol Med 82:137-46.

Cai Y, Ying F, Liu H, Ge L, Song E, Wang L, Zhang D, Hoi Ching Tang E, Xia Z, Irwin MG (2020) Deletion of Rap1 protects against myocardial ischemia/reperfusion injury through suppressing cell apoptosis via activation of STAT3 signaling. FASEB J doi: 10.1096/fj.201901592RR.

Cao CM, Zhang Y, Weisleder N, Ferrante C, Wang X, Lv F, Zhang Y, Song R, Hwang M, Jin L, Guo J, Peng W, Li G, Nishi M, Takeshima H, Ma J, Xiao RP (2010) MG53 constitutes a primary determinant of cardiac ischemic preconditioning. Circulation 121(23):2565-74.

Calamaras TD, Lee C, Lan F, Ido Y, Siwik DA, Colucci WS (2015) The lipid peroxidation product 4-hydroxy-trans-2-nonenal causes protein synthesis in cardiac myocytes via activated mTORC1-p70S6K-RPS6 signaling. Free Radic Biol Med 82:137-46.

Chen H, Shao X, Li L, Zheng C, Xu X, Hong X, Li X, Wu M (2017) Electroacupuncture serum inhibits TNF- $\alpha$-mediated chondrocyte inflammation via the Ras-Raf-MEK1/2-ERK1/2 signaling pathway. Mol Med Rep 16(5):5807-5814.

Chen Q, Jin M, Yang F, Zhu J, Xiao Q, Zhang L (2013) Matrix metalloproteinases: inflammatory regulators of cell behaviors in vascular formation and remodeling. Mediators Inflamm 2013:928315.

Davidson SM, Ferdinandy P, Andreadou I, Bøtker HE, Heusch G, Ibáñez B, Ovize M, Schulz R, Yellon DM, Hausenloy DJ, Garcia-Dorado D (2019) Multitarget Strategies to Reduce Myocardial Ischemia/Reperfusion Injury: JACC Review Topic of the Week. J Am Coll Cardiol 73(1):89-99.

Dern K, Burns TA, Watts MR, van Eps AW, Belknap JK (2019) Influence of digital hypothermia on lamellar events related to IL-6/gp130 signalling in equinesepsis-related laminitis. Equine Vet J doi: 10.1111/evj.13184.

Dai QF, Gao JH, Xin JJ, et al (2019) The Role of Adenosine A2b Receptor in Mediating the Cardioprotection of Electroacupuncture Pretreatment via Influencing Ca2+ Key Regulators. Evid Based Complement Alternat Med 6721286.

Dern K, Burns TA, Watts MR, van Eps AW, Belknap JK (2019) Influence of digital hypothermia on lamellar events related to IL-6/gp130 signalling in equinesepsis-related laminitis. Equine Vet J doi: 10.1111/evj.13184.

Dern K, Burns TA, Watts MR, van Eps AW, Belknap JK (2020) Influence of digital hypothermia on lamellar events related to IL-6/gp130 signalling in equine sepsis-related 
laminitis. Equine Vet. J 52(3).

Ekeloef S, Homilius M, Stilling M, Ekeloef P, Koyuncu S, Münster AB, Meyhoff CS, Gundel O, Holst-Knudsen J, Mathiesen O, Gögenur I (2019) The effect of remote ischaemic preconditioning on myocardial injury in emergency hip fracture surgery (PIXIE trial): phase II randomised clinical trial. BMJ 367:16395.

El-Magd MA, Abdo WS, El-Maddaway M, Nasr NM, Gaber RA, El-Shetry ES, Saleh AA, Alzahrani FAA, Abdelhady DH (2017) High doses of S-methylcysteine cause hypoxia-induced cardiomyocyte apoptosis accompanied by engulfment of mitochondaria by nucleus. Biomed Pharmacother 94:589-597.

Ekeloef S, Homilius M, Stilling M, Ekeloef P, Koyuncu S, Münster AB, Meyhoff CS, Gundel O, Holst-Knudsen J, Mathiesen O, Gögenur I (2019) The effect of remote ischaemic preconditioning on myocardial injury in emergency hip fracture surgery (PIXIE trial): phase II randomised clinical trial. BMJ 367:16395.

Fu SP, He SY, Xu B, Hu CJ, Lu SF, Shen WX, Huang Y, Hong H, Li Q, Wang N, Liu XL, Liang F, Zhu BM (2014) Acupuncture promotes angiogenesis after myocardial ischemia through H3K9 acetylation regulation at VEGF gene. PLoS One 9(4):e94604.

Fu SP, Hong H, Lu SF, Hu CJ, Xu HX, Li Q, Yu ML, Ou C, Meng JZ, Wang TL, Hennighausen L, Zhu BM (2017) Genome-wide regulation of electro-acupuncture on the neural Stat5-loss-induced obese mice. PLoS One 12(8):e0181948.

Friedbichler K, Themanns M, Mueller KM, Schlederer M, Kornfeld JW, Terracciano LM, Kozlov AV, Haindl S, Kenner L, Kolbe T, Mueller M, Snibson KJ, Heim MH, Moriggl R (2012) Growth-hormone-induced signal transducer and activator of transcription 5 signaling causes gigantism, inflammation, and premature death but protects mice from aggressive liver cancer. Hepatology 55(3):941-52.

Geng Y, Chen D, Zhou J, Lu J, Chen M, Zhang H, Wang X (2016) Synergistic Effects of Electroacupuncture and Mesenchymal Stem Cells on Intestinal Ischemia/Reperfusion Injury in Rats. Inflammation 39(4):1414-20.

Heusch G (2015) Molecular basis of cardioprotection: signal transduction in ischemic pre-, post-, and remote conditioning. Circ Res 116(4):674-99.

Huang Y, Lu SF, Hu CJ, Fu SP, Shen WX, Liu WX, Li Q, Wang N, He SY, Liang FR, Zhu BM (2014) Electro-acupuncture at Neiguan pretreatment alters genome-wide gene expressions and protects rat myocardium against ischemia-reperfusion. Molecules 19(10):16158-78.

Huang S, Liu Q, Liao Q, Wu Q, Sun B, Yang Z, Hu X, Tan M, Li L (2018) Interleukin-6/signal transducer and activator of transcription 3 promotes prostate cancer resistance to androgen 
deprivation therapy via regulating pituitary tumor transforming gene 1 expression. Cancer Sci 109(3):678-687.

Hausenloy DJ, Kharbanda RK, Møller UK, et al (2019) Effect of remote ischaemic conditioning on clinical outcomes in patients with acute myocardial infarction (CONDI-2/ERIC-PPCI): a single-blind randomised controlled trial. Lancet 394(10207):1415-1424.

Huang S, Liu Q, Liao Q, Wu Q, Sun B, Yang Z, Hu X, Tan M, Li L (2018) Interleukin-6/signal transducer and activator of transcription 3 promotes prostate cancer resistance to androgen deprivation therapy via regulating pituitary tumor transforming gene 1 expression. Cancer Sci. 109(3):678-687.

Hennighausen L, Robinson GW (2008) Interpretation of cytokine signaling through the transcription factors STAT5A and STAT5B. Genes Dev 22(6):711-21.

Hosui A, Kimura A, Yamaji D, Zhu BM, Na R, Hennighausen L(2009) Loss of STAT5 causes liver fibrosis and cancer development through increased TGF-\{beta\} and STAT3 activation. J Exp Med 206(4):819-31.

Hin Tang JJ, Hao Thng DK, Lim JJ, Toh TB (2020) JAK/STAT signaling in hepatocellular carcinoma. Hepat Oncol 7(1):HEP18.

Harhous Z, Booz GW, Ovize M, Bidaux G, Kurdi M (2019) An Update on the Multifaceted Roles of STAT3 in the Heart. Front Cardiovasc Med 6:150.

Hodge DR, Hurt EM, Farrar WL (2005) The role of IL-6 and STAT3 in inflammation and cancer. Eur J Cancer 41(16):2502-12.

Huynh J, Etemadi N, Hollande F, Ernst M, Buchert M (2017)The JAK/STAT3 axis: A comprehensive drug target for solid malignancies. Semin Cancer Biol 45:13-22.

Huynh J, Chand A, Gough D, Ernst M (2019) Therapeutically exploiting STAT3 activity in cancer - using tissue repair as a road map. Nat. Rev. Cancer 19(2).

Haque I, Ghosh A, Acup S, Banerjee S, Dhar K, Ray A, Sarkar S, Kambhampati S, Banerjee SK (2018), Leptin-induced ER- $\alpha$-positive breast cancer cell viability and migration is mediated by suppressing CCN5-signaling via activating JAK/AKT/STAT-pathway. BMC Cancer 18(1).

Yuan N, Yu G, Liu D, Wang X, Zhao L(2019). An emerging role of interleukin-23 in rheumatoid arthritis. Immunopharmacol Immunotoxicol 41(2):185-191.

Yellon DM, Hausenloy DJ (2017). Myocardial reperfusion injury. N Engl J Med 357(11):1121-35.

Yu JH, Zhu BM, Wickre M, Riedlinger G, Chen W, Hosui A, Robinson GW, Hennighausen L (2010) The transcription factors signal transducer and activator of transcription 5A (STAT5A) and STAT5B negatively regulate cell proliferation through the activation of cyclin-dependent 
kinase inhibitor 2b (Cdkn2b) and Cdkn1a expression. Hepatology 52(5):1808-18.

Ji C, Song F, Huang G, Wang S, Liu H, Liu S, Huang L, Liu S, Zhao J, Lu TJ, Xu F (2018) The protective effects of acupoint gel embedding on rats with myocardial ischemia-reperfusion injury. Life Sci 211:51-62.

Jiang Y, Feng YP, Tang LX, Yan YL, Bai JW (2019) The protective role of NR4A3 in acute myocardial infarction by suppressing inflammatory responses via JAK2-STAT3/NF-kB pathway. Biochem Biophys Res Commun 517(4):697-702.

Janson ND, Jehanathan N, Jung S, Priyathilaka TT, Nam BH, Kim MJ, Lee J (2019) Insight into the molecular function and transcriptional regulation of activator protein 1 (AP-1) components c-Jun/c-Fos ortholog in red lip mullet (Liza haematocheila). Fish Shellfish Immunol 93:597-611.

Ji Z, Liang J, Wu J, Zhang Y, Jia W (2019) Effects of electroacupuncture at Taichong (LR 3) and Baihui (DU 20) on cardiac hypertrophy in rats with spontaneous hypertension. J Tradit Chin Med 39(4):502-508.

Jiang B, Liang P, Wang K, Lv C, Sun L, Tong Z, Liu Y, Xiao X (2014) Nucleolin involved in myocardial ischaemic preconditioning via post-transcriptional control of HSPA1A expression. Cardiovasc. Res 102(1).

Johnson DE， O'Keefe RA， Grandis JR (2018) Targeting the IL-6/JAK/STAT3 signalling axis in cancer. Nat Rev Clin Oncol 15(4).

Kubota A, Suto A, Suzuki K, Kobayashi Y, Nakajima H (2019) Matrix metalloproteinase- 12 produced by Ly6C macrophages prolongs the survival after myocardial infarction by preventing neutrophil influx. J. Mol. Cell. Cardiol 131.

Kim HJ, Park HJ, Hong MS, Song JY, Park HK, Jo DJ, Park SW, HwanYun D, Park HK, Yang JS, Ban JY, Chung JH (2010) Effect by acupuncture on hypothalamic expression of maternally separated rats: proteomic approach. Neurol Res 32 Suppl 1:69-73.

Li Y, Chen B, Yang X, Zhang C, Jiao Y, Li P, Liu Y, Li Z, Qiao B, Bond Lau W, Ma XL, Du J (2019) S100a8/a9 Signaling Causes Mitochondrial Dysfunction and Cardiomyocyte Death in Response to Ischemic/Reperfusion Injury. Circulation 140(9):751-764.

Lu SF, Huang Y, Wang N, Shen WX, Fu SP, Li Q, Yu ML, Liu WX, Chen X, Jing XY, Zhu BM (2016) Cardioprotective Effect of Electroacupuncture Pretreatment on Myocardial Ischemia / Reperfusion Injury via Antiapoptotic Signaling. Evid Based Complement Alternat Med 1-9.

Lai YJ, Tsai JC, Tseng YT, Wu MS, Liu WS, Lam HI, Yu JH, Nozell SE, Benveniste EN (2017) Small G protein Rac GTPases regulate the maintenance of glioblastoma stem-like cells in vitro and in vivo. Oncotarget 8(11):18031-18049. 
Lai YJ, Tsai JC, Tseng YT, Wu MS, Liu WS, Lam HI, Yu JH, Nozell SE, Benveniste EN (2017) Small G protein Rac GTPases regulate the maintenance of glioblastoma stem-like cells in vitro and in vivo. Oncotarget 8(11):18031-18049.

Lindsey ML(2018) Assigning matrix metalloproteinase roles in ischaemic cardiac remodelling. Nat Rev Cardiol 15(8):471-479.

Ma P, Li Y, Wang S, Wang G, Yan C, Li Z, Wang Y, Qin F, Chen L, Fu P (2020) SOCS3 promotes myocardial cell apoptosis in myocardial ischemia reperfusion rats via JAK/STAT signaling pathway. Minerva Cardioangiol.

Meyuhas O (2015) Ribosomal Protein S6 Phosphorylation: Four Decades of Research. Int Rev Cell Mol Biol 320.

Nakao S, Tsukamoto T, Ueyama T, Kawamura T (2020) STAT3 for Cardiac Regenerative Medicine: Involvement in Stem Cell Biology, Pathophysiology, and Bioengineering. Int J Mol Sci 21(6). pii: E1937.

Oba T, Yasukawa H, Hoshijima M, Sasaki K, Futamata N, Fukui D, Mawatari K, Nagata T, Kyogoku S, Ohshima H, Minami T, Nakamura K, Kang D, Yajima T, Knowlton KU, Imaizumi T (2012) Cardiac-specific deletion of SOCS-3 prevents development of left ventricular remodeling after acute myocardial infarction. J Am Coll Cardiol 59(9):838-52.

Obana M, Maeda M, Takeda K, Hayama A, Mohri T, Yamashita T, Nakaoka Y, Komuro I, Takeda K, Matsumiya G, Azuma J, Fujio Y (2010)Therapeutic activation of signal transducer and activator of transcription 3 by interleukin-11 ameliorates cardiac fibrosis after myocardial infarction. Circulation 121(5):684-91.

Painovich J, Longhurst J (2015) Integrating acupuncture into the cardiology clinic: can it play a role? Sheng Li Xue Bao 67(1):19-31.

Pipicz M, Demján V, Sárközy M, Csont T(2018) Effects of Cardiovascular Risk Factors on Cardiac STAT3. Int J Mol Sci 19(11). pii: E3572.

Świerkot J, Sokolik R, Czarny A, Zaczyńska E, Nowak B, Chlebicki A, Korman L, Madej M, Wojtala P, Lubiński Ł, Wiland P (2015) Activity of JAK/STAT and NF-kB in patients with axial spondyloarthritis. Postepy Hig Med Dosw (Online) 69:1291-8.

Sun S, Cui Z, Yan T, Wu J Liu Z (2019) CCN5 inhibits proliferation and promotes apoptosis of oral squamous cell carcinoma cells. Cell Biol Int doi: 10.1002/cbin.11296.

Stobdan T, Zhou D, Ao-Ieong E, Ortiz D, Ronen R, Hartley I, Gan Z, McCulloch AD, Bafna V, Cabrales P, Haddad GG (2015) Endothelin receptor B, a candidate gene from human studies at high altitude, improves cardiac tolerance to hypoxia in genetically engineered heterozygote mice. Proc Natl Acad Sci U S A 112(33):10425-30. 
Sharma S, Mazumder AG, Rana AK, Patial V, Singh D (2019) Spontaneous Recurrent Seizures Mediated Cardiac Dysfunction via mTOR Pathway Upregulation: A Putative Target for SUDEP Management. CNS Neurol Disord Drug Targets 18(7):555-565.

Sulston R, Kelly V, Walker BR, Porter KE, Chapman KE, Gray GA (2017) 11ß-HSD1 suppresses cardiac fibroblast CXCL2, CXCL5 and neutrophil recruitment to the heart post MI. J Endocrinol 233(3):315-327.

Saddic LA, Howard-Quijano K, Kipke J, Kubo Y, Dale EA, Hoover D, Shivkumar K, Eghbali M, Mahajan A (2018) Progression of myocardial ischemia leads to unique changes in immediate-early gene expression in the spinal cord dorsal horn. Am J Physiol Heart Circ Physiol 315(6):H1592-H1601.

Shirakawa K, Endo J, Kataoka M, Katsumata Y, Yoshida N, Yamamoto T, Isobe S, Moriyama H, Goto S, Kitakata H, Hiraide T, Fukuda K, Sano M (2018) IL (Interleukin)-10-STAT3-Galectin-3 Axis Is Essential for Osteopontin-Producing Reparative Macrophage Polarization After Myocardial Infarction. Circulation 138(18):2021-2035.

Shirakawa K, Endo J, Kataoka M, Katsumata Y, Yoshida N, Yamamoto T, Isobe S, Moriyama H, Goto S, Kitakata H, Hiraide T, Fukuda K, Sano M (2018) IL (Interleukin)-10-STAT3-Galectin-3 Axis Is Essential for Osteopontin-Producing Reparative Macrophage Polarization After Myocardial Infarction. Circulation 138(18):2021-2035.

Gupta R, Wood DA (2019) Primary prevention of ischaemic heart disease: populations, individuals, and health professionals. Lancet. 394(10199):685-696.

Gopinath SD (2017) Inhibition of Stat3 signaling ameliorates atrophy of the soleus muscles in mice lacking the vitamin D receptor. Skelet Muscle 7(1):2.

Sharma S, Mazumder AG, Rana AK, Patial V, Singh D (2019) Spontaneous Recurrent Seizures Mediated Cardiac Dysfunction via mTOR Pathway Upregulation: A Putative Target for SUDEP Management. CNS Neurol Disord Drug Targets 18(7):555-565.

Shirakawa K, Endo J, Kataoka M, Katsumata Y, Yoshida N, Yamamoto T, Isobe S, Moriyama H, Goto S, Kitakata H, Hiraide T, Fukuda K, Sano M (2018) IL (Interleukin)-10-STAT3-Galectin-3 Axis Is Essential for Osteopontin-Producing Reparative Macrophage Polarization After Myocardial Infarction. Circulation 138(18):2021-2035.

Tian X, Wang Y, Li S, Yue W, Tian H (2020) ZHX2 inhibits proliferation and promotes apoptosis of human lung cancer cells through targeting p38MAPK pathway. Cancer Biomark 27(1):75-84.

Takahashi J, Yamamoto M, Yasukawa H, Nohara S, Nagata T, Shimozono K, Yanai T, Sasaki T, Okabe K, Shibata T, Mawatari K, Kakuma T, Aoki H, Fukumoto Y (2020) Interleukin-22 Directly Activates Myocardial STAT3 (Signal Transducer and Activator of Transcription-3) 
Signaling Pathway and Prevents Myocardial Ischemia Reperfusion Injury. J Am Heart Assoc 9(8):e014814.

Tang Y, Wang Y, Park KM, Hu Q, Teoh JP, Broskova Z, Ranganathan P, Jayakumar C, Li J, Su H, Tang Y, Ramesh G, Kim IM (2019) MicroRNA-150 protects the mouse heart from ischaemic injury by regulating cell death. J Mol Cell Cardiol 131:41-52.

Tang Q, Zhang SQ, Zheng TT, Li JS, Yin X, Qin P, Li HY (2019) The mechanism of electroacupuncture preconditioning improved myocardial ischemia/reperfusion injury. World journal of integrated Chinese and western medicine 3(14):441-443.

Udoko AN, Johnson CA, Dykan A, Rachakonda G, Villalta F, Mandape SN, Lima MF, Pratap S, Nde PN (2016) Early Regulation of Profibrotic Genes in Primary Human Cardiac Myocytes by Trypanosoma cruzi. PLoS Negl Trop Dis 10(1):e0003747.

Valle-Mendiola A, Soto-Cruz I (2020) Energy Metabolism in Cancer: The Roles of STAT3 and STAT5 in the Regulation of Metabolism-Related Genes. Cancers (Basel) 12(1). pii: E124.

Wu JB, Zhou Y, Liang CL, Zhang XJ, Lai JM, Ye SF, Ouyang H, Lin J, Zhou JY (2017) Cyclovirobuxinum D alleviates cardiac hypertrophy in hyperthyroid rats by preventing apoptosis of cardiac cells and inhibiting the p38 mitogen-activated protein kinase signaling pathway. Chin J Integr Med 23(10).

Wang XT, Wu XD, Lu YX, Sun YH, Zhu HH, Liang JB, He WK, Li L (2018) Egr-1 is involved in coronary microembolization-induced myocardial injury via Bim/Beclin-1 pathway-mediated autophagy inhibition and apoptosis activation. Aging (Albany NY) 10(11):3136-3147.

Wu RM, Jiang B, Li H, Dang WZ, Bao WL, Li HD, Ye G, Shen X (2020) A network pharmacology approach to discover action mechanisms of Yangxinshi Tablet for improving energy metabolism in chronic ischemic heart failure. J Ethnopharmacol 246:112227.

Wen Y, Feng D, Wu H, Liu W, Li H, Wang F, Xia Q, Gao WQ, Kong X (2015) Defective Initiation of Liver Regeneration in Osteopontin-Deficient Mice after Partial Hepatectomy due to Insufficient Activation of IL-6/Stat3 Pathway. Int J Biol Sci 11(10):1236-47.

Wang K, Ju Z, Chen C, Fan S, Pei L, Feng C, Wang F, Cui H, Zhou J (2020) Cardioprotective effect of electroacupuncture in cardiopulmonary bypass through apelin/APJ signaling. Life Sci. 242:117208

Wingelhofer B, Neubauer HA, Valent P, Han X, Constantinescu SN, Gunning PT, Müller M, Moriggl R (2018). Implications of STAT3 and STAT5 signaling on gene regulation and chromatin remodeling in hematopoietic cancer. Leukemia 32(8):1713-1726.

Walker SR, Xiang M, Frank DA (2014) Distinct roles of STAT3 and STAT5 in the pathogenesis and targeted therapy of breast cancer. Mol Cell Endocrinol 382(1):616-621. 
Walker SR, Nelson EA, Yeh JE, Pinello L, Yuan GC, Frank DA (2013) STAT5 outcompetes STAT3 to regulate the expression of the oncogenic transcriptional modulator BCL6. Mol Cell Biol. 33(15):2879-90.

Walker SR, Xiang M, Frank DA (2014) STAT3 Activity and Function in Cancer: Modulation by STAT5 and miR-146b. Cancers (Basel) 6(2):958-68.

Wen Z, Liu Q, Wu J, Xu B, Wang J, Liang L, Guo Y, Peng M, Zhao Y, Liao Q (2019) Fibroblast activation protein $\alpha$-positive pancreatic stellate cells promote the migration and invasion of pancreatic cancer by CXCL1-mediated Akt phosphorylation. Ann Transl Med 7(20):532.

Wen Y, Feng D, Wu H, Liu W, Li H, Wang F, Xia Q, Gao WQ, Kong X (2015) Defective Initiation of Liver Regeneration in Osteopontin-Deficient Mice after Partial Hepatectomy due to Insufficient Activation of IL-6/Stat3 Pathway. Int J Biol Sci 11(10):1236-47.

Wu RM, Jiang B, Li H, Dang WZ, Bao WL, Li HD, Ye G, Shen X (2020) A network pharmacology approach to discover action mechanisms of Yangxinshi Tablet for improving energy metabolism in chronic ischemic heart failure. J Ethnopharmacol 246:112227.

Wingelhofer B, Neubauer HA, Valent P, Han X, Constantinescu SN, Gunning PT, Müller M, Moriggl R (2018) Implications of STAT3 and STAT5 signaling on gene regulation and chromatin remodeling in hematopoietic cancer. Leukemia 32(8):1713-1726.

Walker SR, Xiang M, Frank DA (2014) Distinct roles of STAT3 and STAT5 in the pathogenesis and targeted therapy of breast cancer. Mol Cell Endocrinol 382(1):616-621.

Walker SR, Nelson EA, Yeh JE, Pinello L, Yuan GC, Frank DA (2013) STAT5 outcompetes STAT3 to regulate the expression of the oncogenic transcriptional modulator BCL6. Mol Cell Biol 33(15):2879-90.

Wilhide ME, Tranter M, Ren X, Chen J, Sartor MA, Medvedovic M, Jones WK (2011)

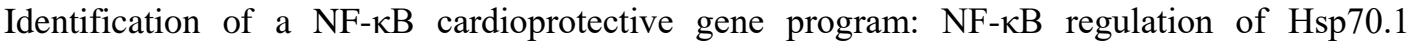
contributes to cardioprotection after permanent coronary occlusion. J. Mol. Cell. Cardiol 51(1).

Zhang T, Yang WX, Wang YL, Yuan J, Qian Y, Sun QM, Yu ML, Fu SP, Xu B, Lu SF (2020) Electroacupuncture preconditioning attenuates acute myocardial ischemia injury through inhibiting NLRP3 inflammasome activation in mice. Life Sci 248:117451.

Zeng Q, He H, Wang XB, Zhou YQ, Lin HX, Tan ZP, He SF, Huang GZ (2018) Electroacupuncture Preconditioning Improves Myocardial Infarction Injury via Enhancing AMPK-Dependent Autophagy in Rats. Biomed Res Int 2018:1238175.

Zhai CG, Xu YY, Tie YY, Zhang Y, Chen WQ, Ji XP, Mao Y, Qiao L, Cheng J, Xu QB, Zhang C (2018) DKK3 overexpression attenuates cardiac hypertrophy and fibrosis in an angiotensin-perfused animal model by regulating the ADAM17/ACE2 and GSK-3 $\beta / \beta$-catenin 
pathways. J Mol Cell Cardiol 114:243-252.

Zhu XM, Sun WF (2017) Association between matrix metalloproteinases polymorphisms and ovarian cancer risk: A meta-analysis and systematic review. PLoS One 12(9):e0185456.

Zhang T, Yang WX, Wang YL,et al (2020) Electroacupuncture preconditioning attenuates acute myocardial ischemia injury through inhibiting NLRP3 inflammasome activation in mice. Life Sci. 248:117451.

Zhao L, Li D, Zheng H, et al (2019) Acupuncture as Adjunctive Therapy for Chronic Stable Angina: A Randomized Clinical Trial[J]. JAMA Intern Med doi: 10.1001/jamainternmed.

Zhou X, Xia N, Lv B, Tang T, Nie S, Zhang M, Jiao J, Liu J, Xu C, Hou G, Yang X, Hu Y, Liao Y, Cheng X (2020) Interleukin 35 ameliorates myocardial ischemia-reperfusion injury by activating the gp130-STAT3 axis. FASEB J doi: 10.1096/fj.201901718RR.

Zhen Z, Li Y, Jinhua Y, Zhen KW, and Gang D (2018) PI3K/Akt and HIF-1 signaling pathway in hypoxia-ischemia. Published online. 
Table 1. The top 30 differentially expressed genes with a $\log 2(\mathrm{FC})>| \pm 1|$ and $\mathrm{q}$ value $<0.05$

A. The top 30 differentially expressed genes obtained from comparing Stat $5^{f / f l}+\mathrm{EA}+\mathrm{I} / \mathrm{R}$ vs Stat $^{f l / f l}+\mathrm{I} / \mathrm{R}$

\begin{tabular}{|c|c|c|c|c|c|c|c|}
\hline \multicolumn{4}{|c|}{ Up-regulated in EA against I/R } & \multicolumn{4}{|c|}{ down-regulated in EA against I/R } \\
\hline $\begin{array}{l}\text { Gene } \\
\text { name }\end{array}$ & value_1 & value_2 & $\begin{array}{c}\log 2 \\
\text { (fold_change) }\end{array}$ & $\begin{array}{l}\text { Gene } \\
\text { name }\end{array}$ & value_1 & value_2 & $\begin{array}{c}\log 2 \\
\text { (fold_change) }\end{array}$ \\
\hline Fosb & 0.181422 & 27.5826 & 7.24827 & Hbb-bt & 35.5975 & 1.35656 & -4.71375 \\
\hline Retnlg & 1.26857 & 106.281 & 6.38853 & Tcf15 & 53.5841 & 3.7788 & -3.82581 \\
\hline Crisp1 & 1.13838 & 82.4984 & 6.17931 & Cen5 & 6.67781 & 0.624545 & -3.4185 \\
\hline Fos & 1.59922 & 114.642 & 6.16363 & Myl4 & 60.998 & 5.99943 & -3.34586 \\
\hline Cxcl5 & 0.375871 & 21.1825 & 5.81649 & Scand1 & 105.37 & 11.7828 & -3.16071 \\
\hline Selp & 0.314312 & 16.2764 & 5.69443 & Zhx2 & 1.93407 & 0.220615 & -3.13204 \\
\hline Cxcl1 & 1.96399 & 95.2442 & 5.59977 & Nrtn & 43.6184 & 5.0225 & -3.11846 \\
\hline S100a8 & 5.82634 & 256.694 & 5.46131 & Tnfrsf25 & 3.90054 & 0.503182 & -2.95452 \\
\hline Atf3 & 2.46681 & 106.299 & 5.42933 & Pttg1 & 33.8997 & 4.94227 & -2.77803 \\
\hline Ptx3 & 0.51755 & 19.8976 & 5.26476 & Zfp771 & 19.5158 & 3.02169 & -2.69122 \\
\hline $\mathrm{Nr} 4 \mathrm{a} 3$ & 0.472838 & 17.3526 & 5.19767 & Fzd2 & 3.1422 & 0.491571 & -2.6763 \\
\hline Sele & 0.190666 & 6.83815 & 5.16449 & Fxyd3 & 3.78128 & 0.621019 & -2.60617 \\
\hline Socs 3 & 2.33823 & 83.0272 & 5.1501 & Aplnr & 15.2807 & 2.89142 & -2.40186 \\
\hline Egr1 & 3.52759 & 122.674 & 5.12 & Cited4 & 17.5033 & 3.57884 & -2.29006 \\
\hline S100a9 & 11.0427 & 381.325 & 5.10986 & Eva1b & 18.5641 & 3.80599 & -2.28617 \\
\hline Il18rap & 0.0722091 & 2.21294 & 4.93764 & Msx1 & 3.34857 & 0.6924 & -2.27387 \\
\hline Thbs1 & 1.59068 & 41.5123 & 4.70582 & Dkk3 & 5.70321 & 1.21389 & -2.23213 \\
\hline Rdh12 & 0.122831 & 3.01114 & 4.61557 & Rnaset $2 \mathrm{a}$ & 22.5668 & 4.88218 & -2.2086 \\
\hline Hspa1b & 2.40171 & 58.418 & 4.60428 & Ifi2712a & 180.402 & 39.5256 & -2.19036 \\
\hline Hspa1a & 1.99294 & 44.6613 & 4.48606 & Nrarp & 11.2641 & 2.52363 & -2.15815 \\
\hline Adam8 & 0.400678 & 8.43168 & 4.39531 & Kctd15 & 2.65098 & 0.611701 & -2.11563 \\
\hline Ch25h & 0.769351 & 15.8707 & 4.36658 & Hic1 & 7.47804 & 1.74196 & -2.10195 \\
\hline Nts & 0.799365 & 15.3258 & 4.26096 & Gas 1 & 16.0842 & 3.82293 & -2.07289 \\
\hline Ifitm6 & 1.20354 & 22.6423 & 4.23367 & Oas1a & 3.5286 & 0.843947 & -2.06387 \\
\hline Egr2 & 0.16011 & 3.01005 & 4.23265 & Dynll1 & 78.6361 & 18.9174 & -2.05548 \\
\hline
\end{tabular}




\begin{tabular}{cccccccc}
\hline Arc & 1.14086 & 20.7638 & 4.18587 & Trim47 & 26.4865 & 6.40037 & -2.04903 \\
Agt & 1.55521 & 27.442 & 4.1412 & Tmsb10 & 110.513 & 26.7491 & -2.04665 \\
Rnd1 & 0.793702 & 12.8902 & 4.02154 & B3gnt3 & 2.39685 & 0.580215 & -2.04648 \\
Pdk4 & 35.6426 & 578.857 & 4.02153 & Myo7a & 2.29499 & 0.574977 & -1.99691 \\
Plaur & 1.59226 & 25.5567 & 4.00455 & Fam181b & 3.87361 & 0.976908 & -1.98738 \\
\hline
\end{tabular}

B. The top 30 differentially expressed genes obtained from comparing Stat5-cKO+EA+I/R vs.

Stat5-cKO+I/R

\begin{tabular}{|c|c|c|c|c|c|c|c|}
\hline \multicolumn{4}{|c|}{ Up-regulated in EA against I/R } & \multicolumn{4}{|c|}{ Down-regulated in EA against I/R } \\
\hline $\begin{array}{l}\text { Gene } \\
\text { name }\end{array}$ & value_1 & value_2 & $\begin{array}{c}\log 2 \\
\text { (fold_change) }\end{array}$ & $\begin{array}{l}\text { Gene } \\
\text { name }\end{array}$ & \multicolumn{2}{|c|}{ value_1 value_2 } & $\begin{array}{c}\log 2 \\
\text { (fold_change) }\end{array}$ \\
\hline Eno1b & 0.503646 & 6.53728 & 3.69821 & Olfr1033 & 855.24 & 3.24857 & -8.04038 \\
\hline Dynlt1b & 1.11668 & 14.442 & 3.69299 & Gm45551 & 221.558 & 1.31604 & -7.39534 \\
\hline $\mathrm{H} 2-\mathrm{Q} 1$ & 0.264109 & 3.03007 & 3.52015 & Gm38271 & 30.2569 & 0.353232 & -6.4205 \\
\hline Tmem181c-ps & 0.99792 & 11.1342 & 3.47994 & Psg 16 & 2.41103 & 0.0719611 & -5.06629 \\
\hline Gm4737 & 0.445121 & 4.58914 & 3.36595 & Gm3365 & 7.26917 & 0.262255 & -4.79275 \\
\hline 2610005L07Rik & 1.25086 & 12.1968 & 3.28551 & Sugct & 11.7515 & 0.52977 & -4.47133 \\
\hline Gm14421 & 0.377049 & 3.17075 & 3.072 & Gm43197 & 55.389 & 3.11501 & -4.15229 \\
\hline Mmp3 & 0.379936 & 3.17412 & 3.06253 & Gm15280 & 32.1097 & 2.05499 & -3.96581 \\
\hline Gm42887 & 0.544175 & 4.41682 & 3.02087 & CAAA01147332.1 & 97.5278 & 7.86365 & -3.63254 \\
\hline Ubb & 35.8823 & 290.433 & 3.01686 & Zfp729a & 6.97773 & 0.621896 & -3.48801 \\
\hline $\mathrm{Hba}-\mathrm{a} 2$ & 44.9947 & 363.254 & 3.01315 & Adgra3 & 25.8651 & 3.26536 & -2.98569 \\
\hline Tmem191c & 0.28056 & 2.17679 & 2.95582 & Fmod & 3.18759 & 0.452927 & -2.81512 \\
\hline Gdnf & 0.160275 & 1.21115 & 2.91776 & Dpy1913 & 2.2277 & 0.347531 & -2.68034 \\
\hline Rpl3-ps1 & 3.02696 & 22.6124 & 2.90117 & Gm37324 & 1.86878 & 0.299513 & -2.64141 \\
\hline Stbd1 & 0.465139 & 3.32577 & 2.83795 & Gm48274 & 72.516 & 11.6454 & -2.63854 \\
\hline Adh6b & 0.422625 & 3.00224 & 2.82859 & Pilra & 3.10358 & 0.507 & -2.61387 \\
\hline Hba-a1 & 78.1547 & 542.904 & 2.79629 & Prc1 & 1.51292 & 0.247267 & -2.6132 \\
\hline Polr21 & 6.80429 & 43.8946 & 2.68952 & Clec4e & 6.2329 & 1.08171 & -2.52658 \\
\hline Myh7 & 174.331 & 1091.89 & 2.64692 & Spp1 & 3.08682 & 0.543414 & -2.506 \\
\hline Gapdh & 603.792 & 3577.93 & 2.567 & Rac2 & 14.0493 & 2.49669 & -2.49241 \\
\hline Pttg1 & 5.6626 & 32.9153 & 2.53922 & Oxnad1 & 117.772 & 21.1786 & -2.47532 \\
\hline $\mathrm{Zc} 3 \mathrm{~h} 3$ & 0.178519 & 1.03346 & 2.53333 & Fggy & 4.18537 & 0.772849 & -2.4371 \\
\hline
\end{tabular}




\begin{tabular}{rrrrrrrr}
\hline Gm6472 & 5.6958 & 31.1981 & 2.45349 & Gm44215 & 2.03074 & 0.376049 & -2.43301 \\
Cys1 & 0.799506 & 4.37525 & 2.45218 & Lars2 & 129.273 & 25.3961 & -2.34774 \\
Tgtp2 & 0.951374 & 5.16733 & 2.44134 & Zfp975 & 3.23415 & 0.636673 & -2.34476 \\
Rps6 & 94.127 & 497.199 & 2.40114 & Bace2 & 8.13204 & 1.6647 & -2.28836 \\
Hspa1a & 20.8766 & 109.614 & 2.39248 & Suds3 & 101.31 & 22.7191 & -2.1568 \\
Eif3j2 & 0.89728 & 4.63881 & 2.37012 & Tesk1 & 11.7699 & 2.74535 & -2.10004 \\
Gm8116 & 1.05436 & 5.39728 & 2.35587 & Insig2 & 86.0597 & 20.4798 & -2.07113 \\
Gm15459 & 34.4931 & 176.148 & 2.35241 & Pnkp & 30.3154 & 7.36189 & -2.0419 \\
\hline
\end{tabular}



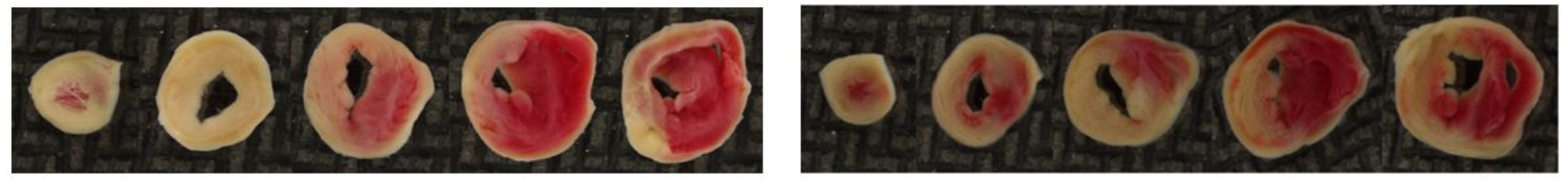

Stat5 $f^{f / / 1}+\mathrm{EA}+\mathrm{I} / \mathrm{R}$

Stat5-cKO+EA+l/R
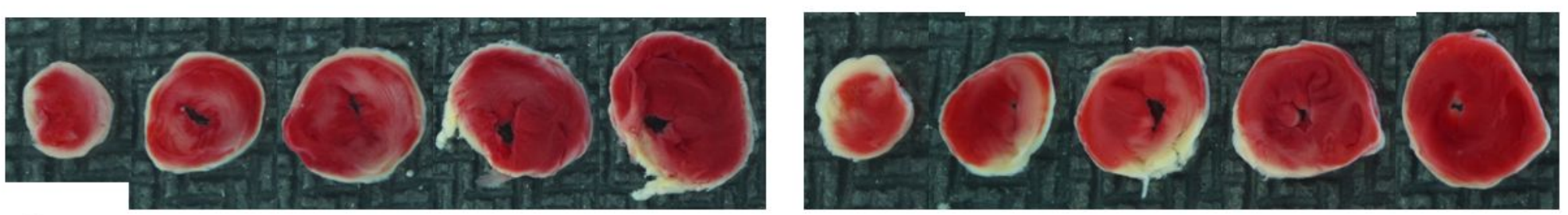

B $\underline{\underline{D}}$

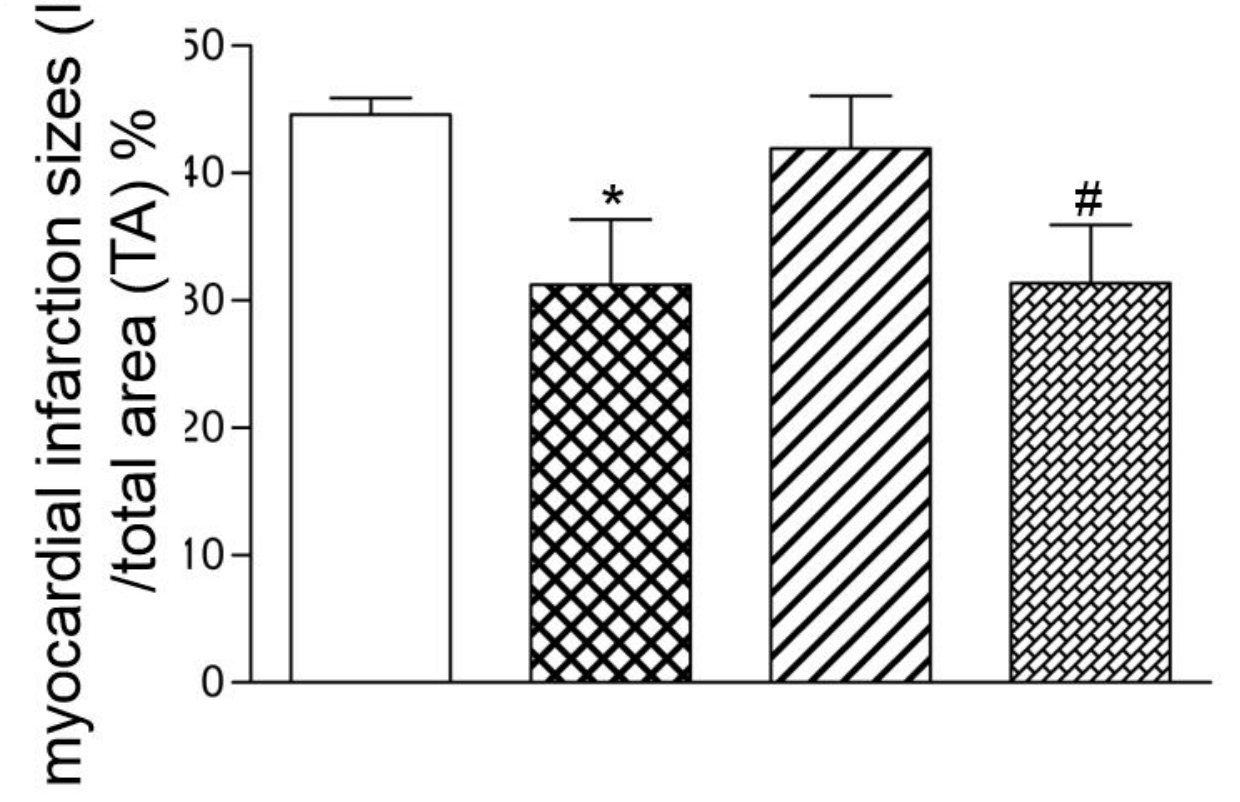

$\square$ Stat5 $^{f / f|+|}+1 / \mathrm{R}$

$\otimes S^{2} t a t 5^{f / f t}+\mathrm{EA}+\mathrm{l} / \mathrm{R}$

Z Stat5-cKO+I/R

Stat5-cKO+EA+l/R $\mathrm{n}=5$ 
A

$S t a t 5^{f / / f l+1 / R} \quad S t a t 5^{f / f \mid}+E A+|/ R \quad S t a t 5-c K O+| / R \quad S t a t 5-c K O+E A+\mid / R$

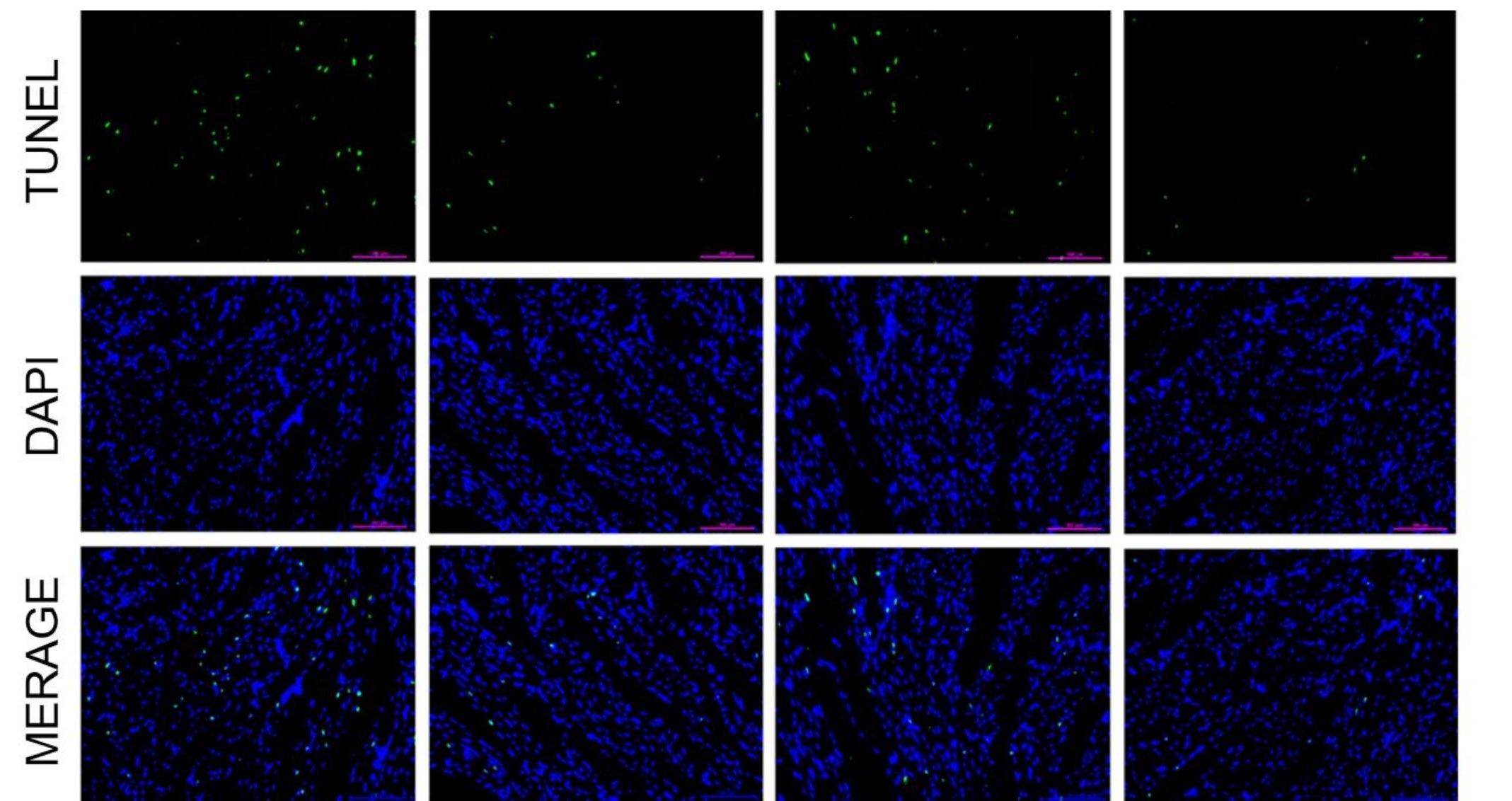




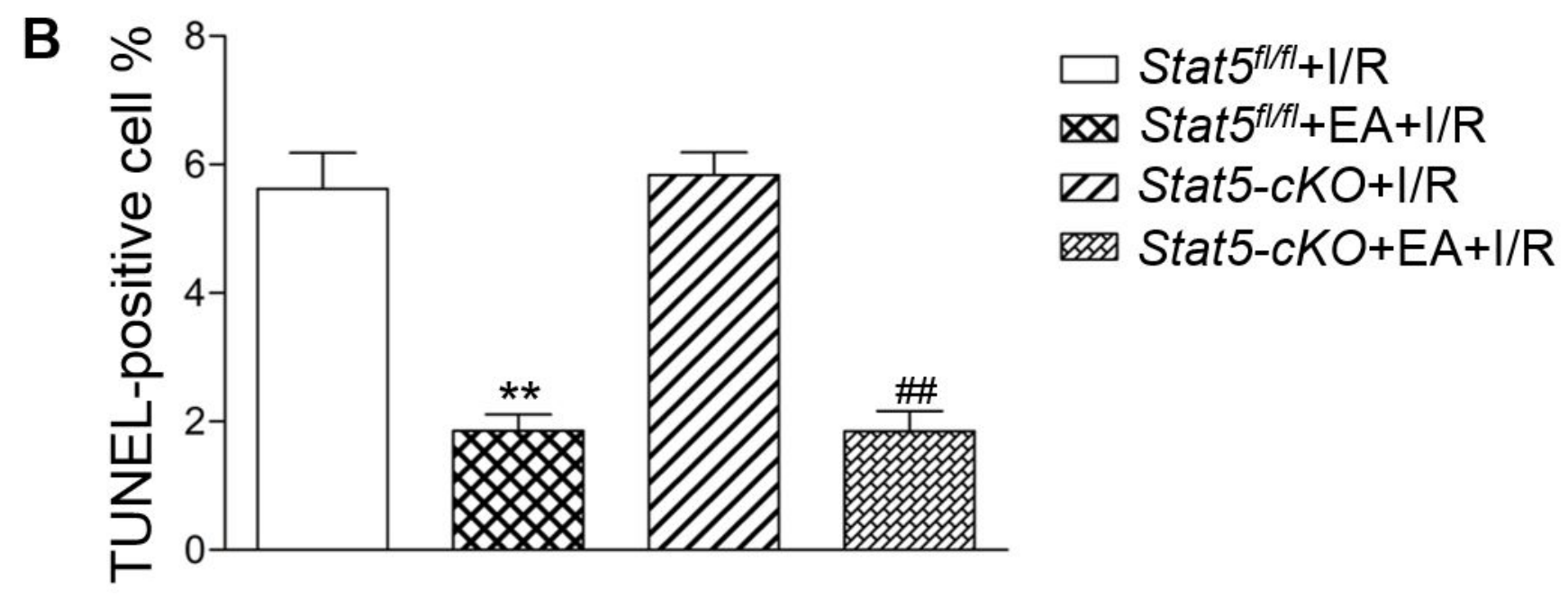


A Stat5 ${ }^{f / f l} \quad$ Stat $5^{f / f l}$ Stat5-cKO Stat5-cKO
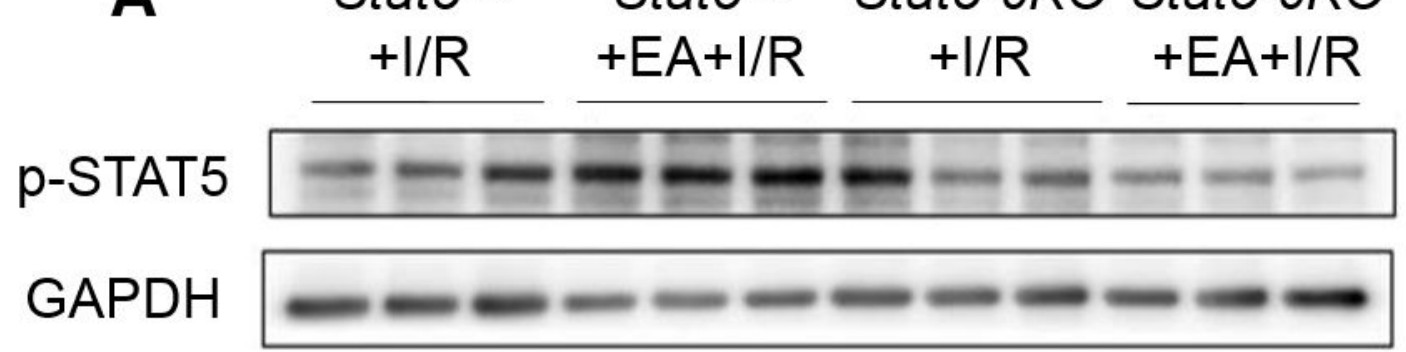

B

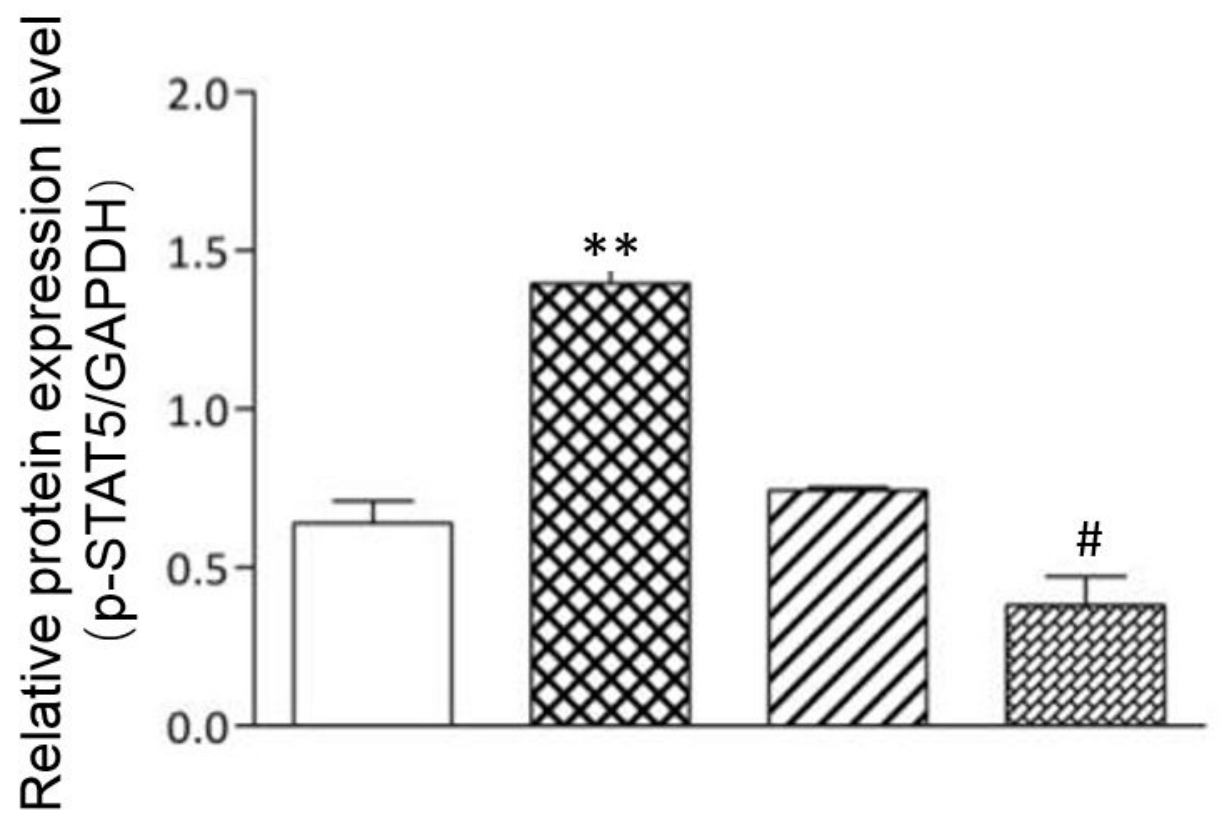

$\square \operatorname{Stat}^{\text {ff/fII }+1 / R}$ Stat5 ${ }^{f / / f}+\mathrm{EA}+\mathrm{I} / \mathrm{R}$ ZZ Stat5-cKO+l/R Stat5-cKO+EA+l/R 


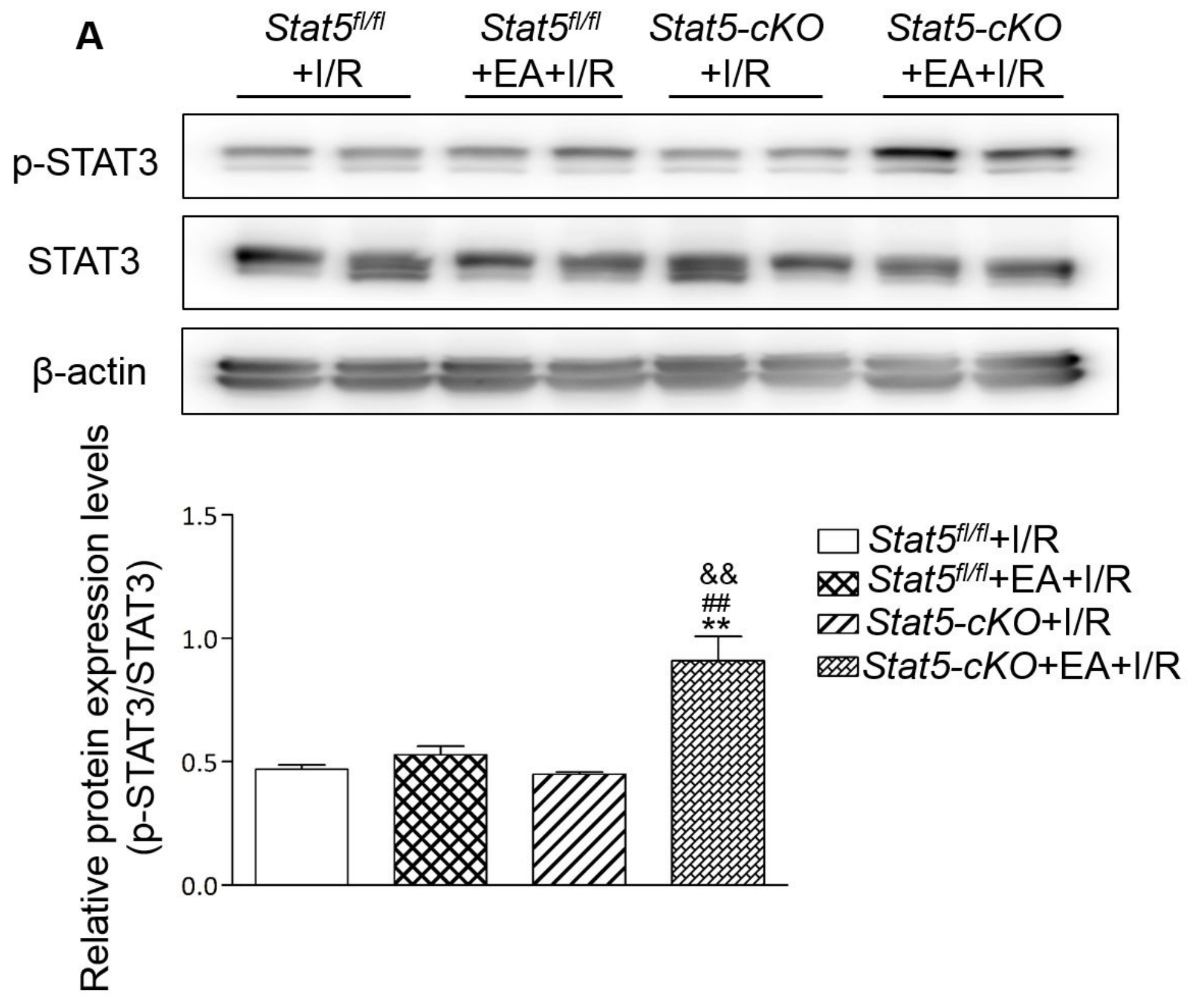


B

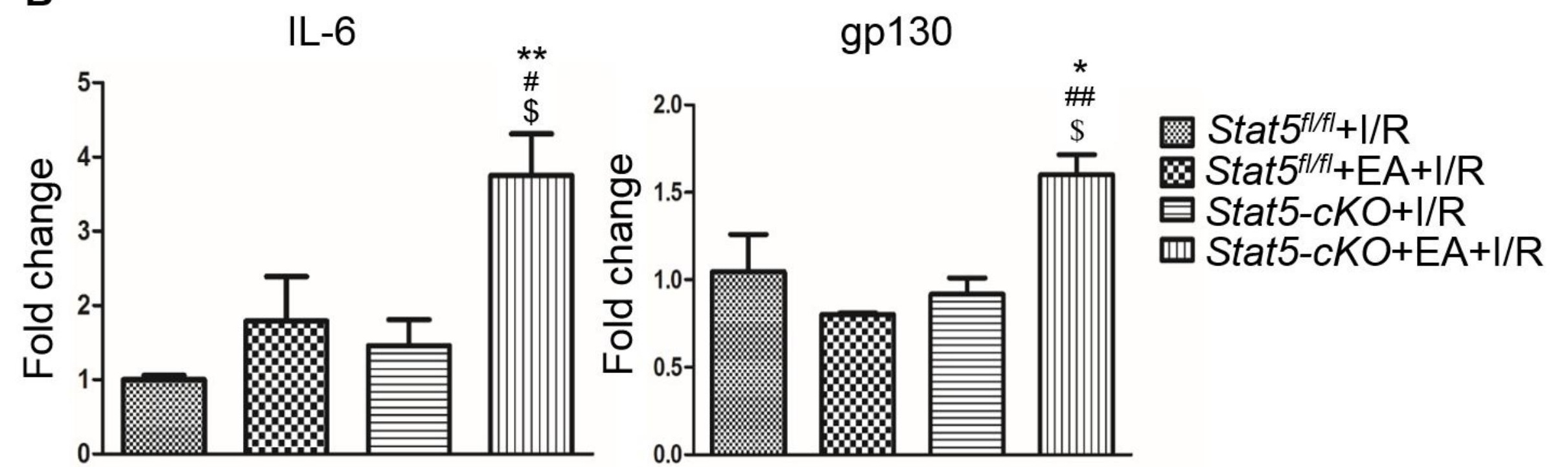


Stat $5^{f / / f}+1 / R$ vs Stat5 ${ }^{f / / f I}+\mathrm{EA}+\mathrm{I} / \mathrm{R}$

919(46.9\%)

\section{6(46.3\%)}

Stat5-cKO+I/R vs Stat5-cKO+EA+I/R 
A JAK-STAT signaling pathway

TNF signaling pathway

Cytokine-cytokine receptor int

Transcriptional misregulation

IL-17 signaling pathway

Hematopoietic cell lineage AGE-RAGE signaling pathway in

Malaria
Insulin resistance

Adipocytokine signaling pathwa

Apoptosis

Proteoglycans in cancer

Influenza A

NF-kappa B signaling pathway

MAPK signaling pathway

Small cell lung cancer p53 signaling pathway PI3K-Akt signaling pathway

Rheumatoid arthritis HIF-1 signaling pathway

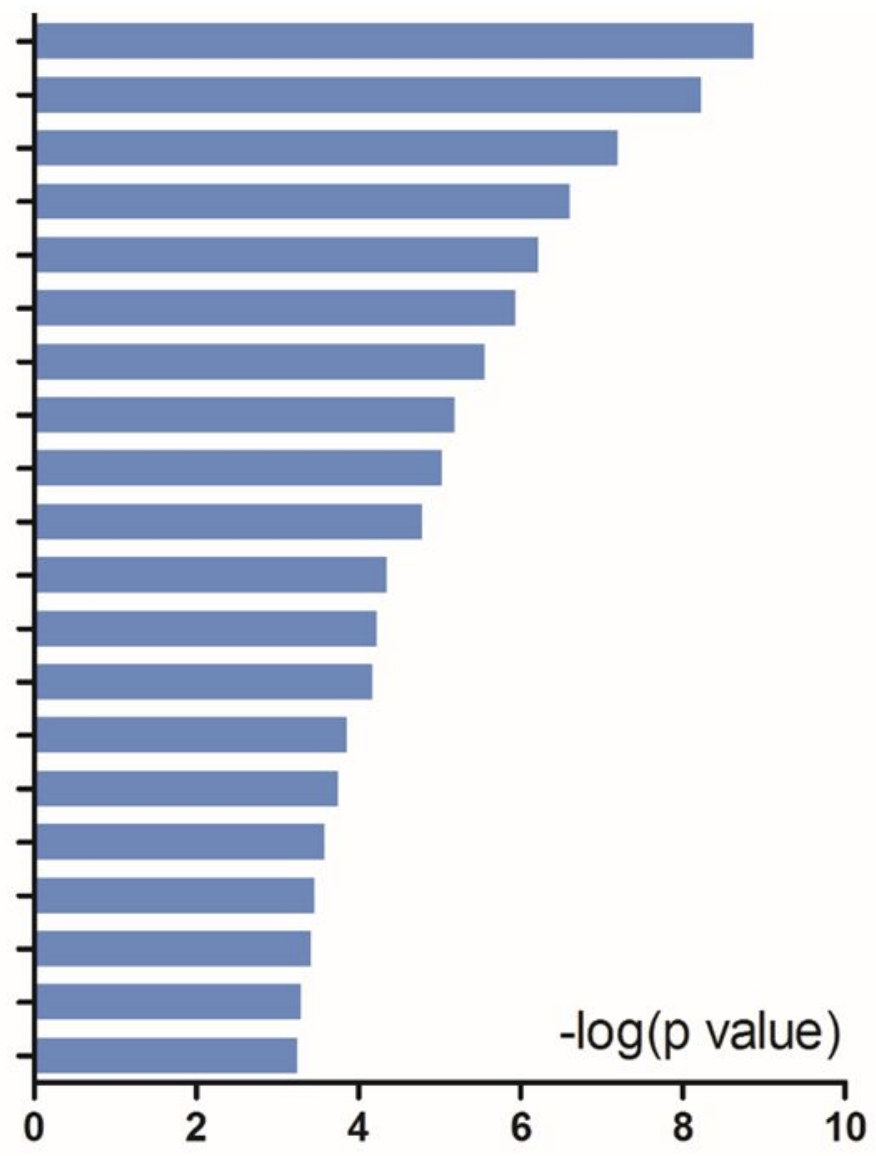


Oxidative phosphorylation -

Parkinson disease Glutathione metabolism Huntington disease HIF-1 signaling pathway Alzheimer disease Phagosome Ferroptosis RNA degradation Retrograde endocannabinoid sig Phenylalanine metabolism RNA transport Leishmaniasis Non-alcoholic fatty liver dise Morphine addiction Legionellosis Proteasome Galactose metabolism

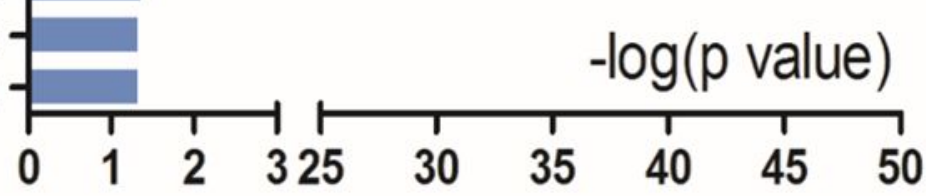


IL-17 signaling pathway MAPK signaling pathway Human T-cell leukemia virus 1 Relaxin signaling pathway Spliceosome Estrogen signaling pathway Measles Breast cancer Antigen processing and present TNF signaling pathway Phagosome Amphetamine addiction Apoptosis Kaposi sarcoma-associated herp $B$ cell receptor signaling path Epstein-Barr virus infection Prion diseases PD-L1 expression and PD-1 chec Colorectal cancer

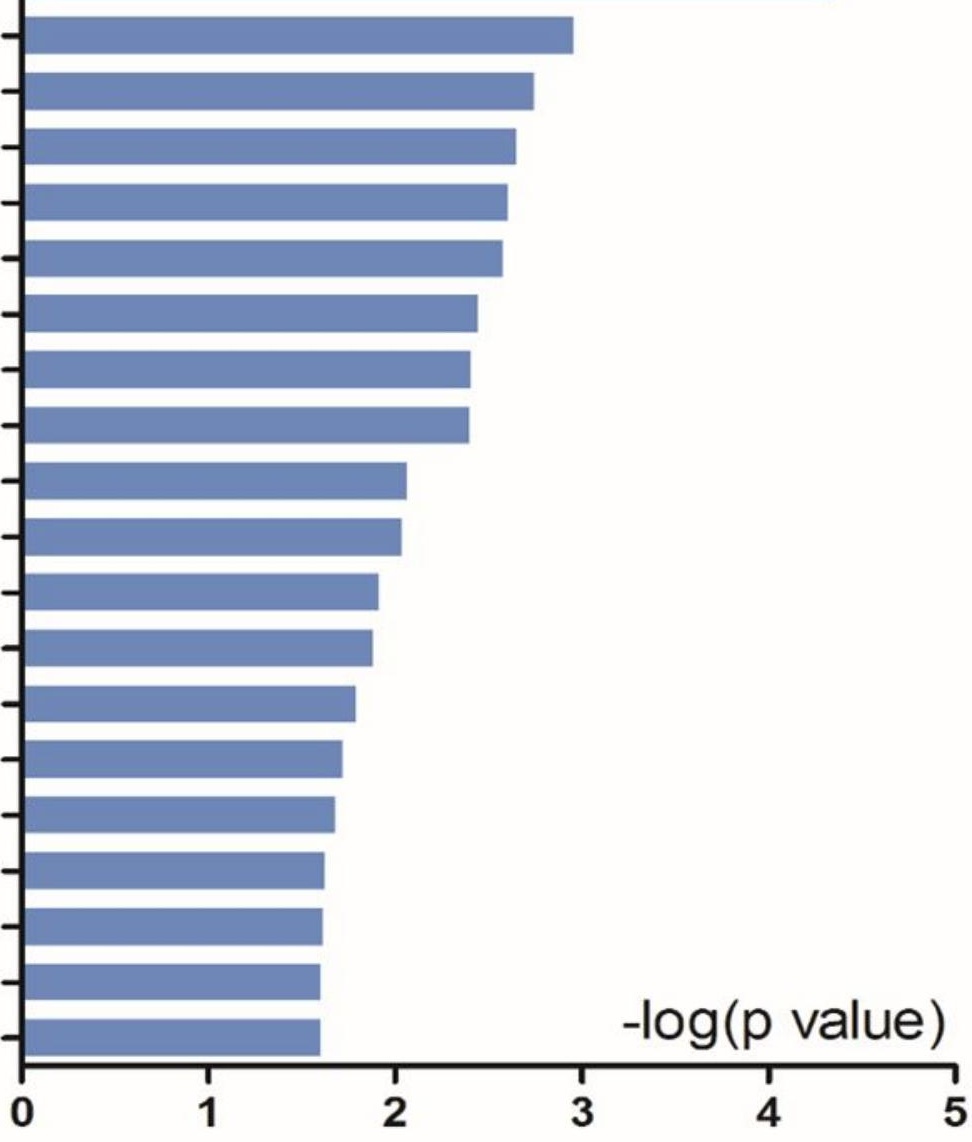




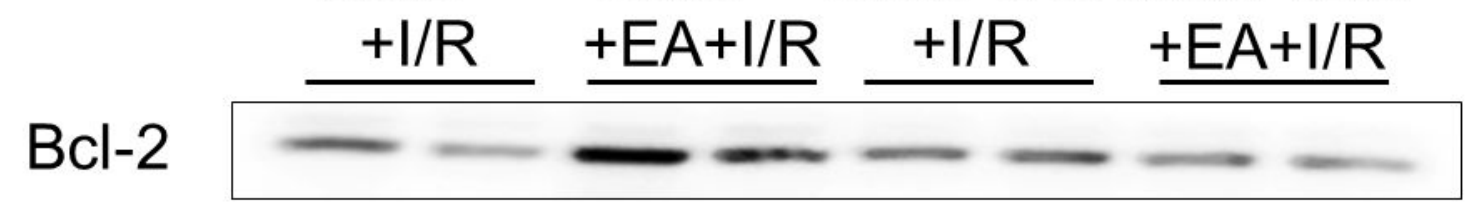

$\mathrm{Bcl}-\mathrm{xL}=-\div$

Cyt c

GAPDH

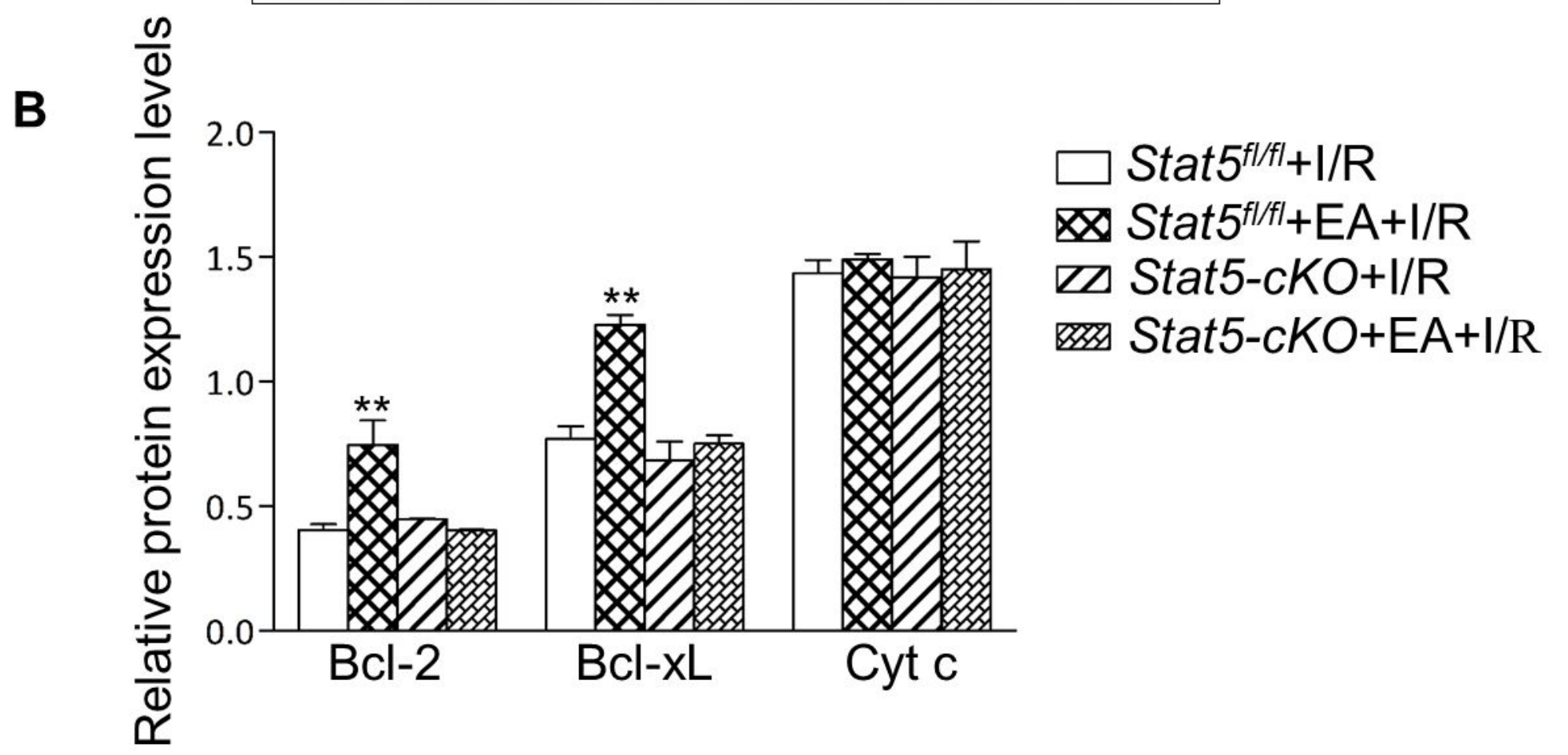


A

Stat5 $5^{f / f l} \quad$ Stat5 $5^{f / f l}$ Stat5-cKO Stat5-cKO

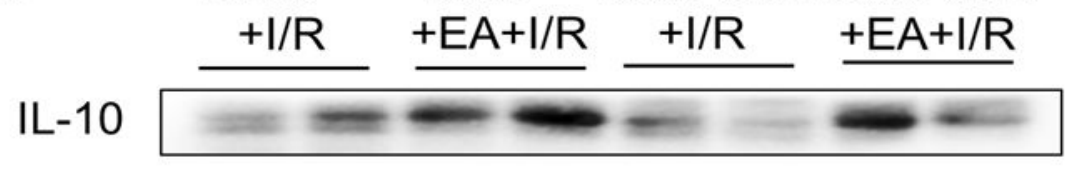

p-AKT

AKT

GAPDH

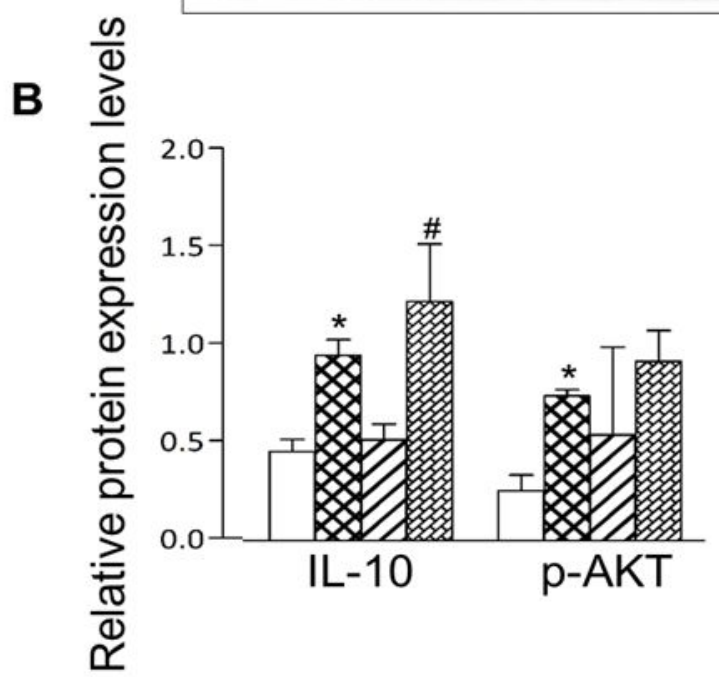

$\square$ Stat $5^{f|/ f|+\mid / R}$ $\otimes S^{2} t a t 5^{f / f l}+\mathrm{EA}+\mathrm{I} / \mathrm{R}$ a S Stat5-cKO+l/R Stat5-cKO+EA+l/R 
Stat5 ${ }^{f / / f l} \quad$ Stat5 $5^{f / f l} \quad$ Stat5- Stat5-cKO

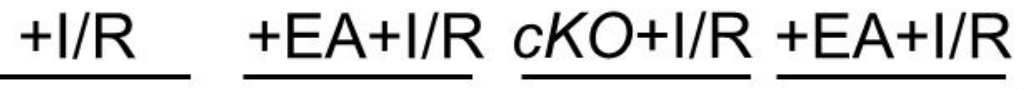

VEGFA

GAPDH

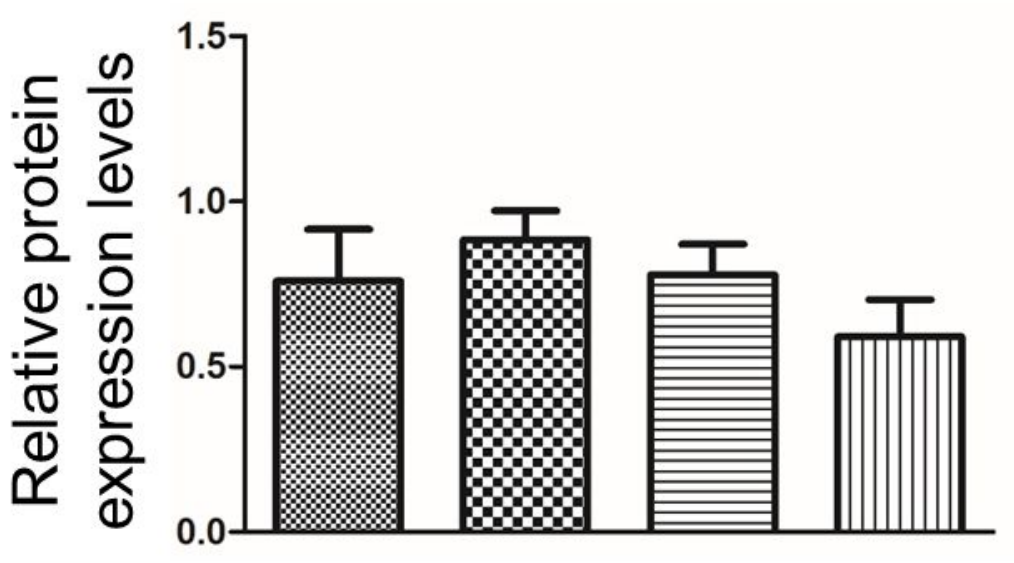

网 Stat $5^{f / f|f|+\mid / R}$

खStat5 ${ }^{f / / f l}+\mathrm{EA}+\mathrm{l} / \mathrm{R}$

首Stat5-cKO+l/R

四Stat5-cKO+EA+I/R 